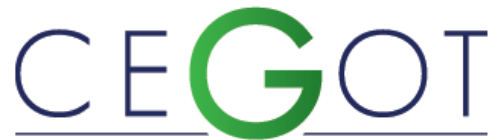

Centro de Estudos de Geografia e Ordenamento do Território
Geografia e Ordenamento do Território, Revista Eletrónica Centro de Estudos de Geografia e Ordenamento do Território http://cegot.org

BALTAR, CLÁUDIA

Universidade Estadual de Londrina, Departamento de Ciências Sociais/Centro de Letras e Ciências Humanas/Observatório das Migrações de Londrina

Rodovia Celso Garcia Cid, Km 380, s/n - Campus Universitário, Londrina - PR, 86057-970, Brasil cbaltar@uel.br

\section{BALTAR, RONALDO}

Universidade Estadual de Londrina, Departamento de Ciências Sociais/Centro de Letras e Ciências Humanas/Observatório das Migrações de Londrina

86.057-970, Londrina, Paraná, Brasil baltar@uel.br

\title{
Debatendo a criação de municípios na contemporaneidade: considerações a partir da urbanização e da participação dos pequenos municípios no Brasil e no Paraná Debating the creation of municipalities in contemporary times: considerations based on urbanization and the participation of small municipalities in Brazil and Paraná
}

Referência: Baltar, Cláudia; Baltar, Ronaldo (2018). Debatendo a criação de municípios na contemporaneidade: considerações a partir da urbanização e da participação dos pequenos municípios no Brasil e no Paraná. Revista de Geografia e Ordenamento do Território (GOT), n. ${ }^{\circ} 14$ (setembro). Centro de Estudos de Geografia e Ordenamento do Território, p. 71-107, dx.doi.org/10.17127/got/2018.14.003

\section{RESUMO}

O objetivo desse artigo é desenvolver uma reflexão sobre o processo de criação de municípios no Brasil, temática que ganhou evidência ao longo da década de 1990, vinculada ao fortalecimento dos municípios como entidade federativa autônoma, no contexto pós Constituição de 1988, mas que encontra-se esquecido na atualidade. Considera-se a retomada do tema algo importante para se evidenciar o papel desempenhado pelas municipalidades, em especial os pequenos municípios, no processo de urbanização e de estrutura da rede de cidades no país. $O$ estudo mobilizará dados demográficos, de criação de municípios e indicadores de qualidade de vida, para o Brasil e estado do Paraná, de 1900 a 2010. Entre as conclusões, destaca-se a importância de não se perder de vista as dimensões da autonomia política e da participação da sociedade civil em tomadas de decisão tão complexas como as que envolvem criação e fusão de municípios.

Palavras-chave: Criação de municípios; urbanização; rede de cidade; pequenos municípios; estado do Paraná

\section{ABSTRACT}

This article intends to present a reflection about the process of creating municipalities in Brazil. This topic gained evidence after the 1988 Brazilian Constitution promulgation, where the municipalities emerged as an autonomous federal entity. But this aspect is currently forgotten among the specialist that debate the issues correlated to Brazilian municipalities creation. The present research considers important to highlight the role of Brazilian 
municipalities, especially the small ones, to understand the urban network structures formation. The study mobilizes demographic data, quality of life indicators and information about municipalities creation, comparing Brazil and the state of Paraná, from 1900 to 2010. Among the conclusions, the article points out the autonomy and the civil society participation as important political dimensions in the decision-making process of creation and merging municipalities in Brazil.

Keywords: Creation of municipalities; urbanization; city network; small municipalities; state of Parana

\section{Introdução}

Desde o início da colonização do Brasil, a efetivação da ocupação do território realizou-se, principalmente, através da fundação de vilas e cidades e, posteriormente, com a promulgação da República, em fins do século XIX, a partir do processo de criação de novos municípios. Assim, a criação de novas vilas, cidades e municípios acompanhou o processo de desenvolvimento econômico do país, constituindo-se na expressão do dinamismo econômico e demográfico de diferentes porções no território nacional, em diferentes contextos econômicos, políticos e sociais ${ }^{1}$.

Dessa forma, considerando o modo como se processaram a colonização e a ocupação do país, tem-se que a rede de cidades se desenvolveu, durante os três primeiros séculos de ocupação, bastante concentrada na faixa costeira do país, especialmente na região Nordeste, nos estados de Bahia e Pernambuco. Na metade do século XVII, essa concentração econômica e demográfica correspondente começa a vivenciar uma mudança de eixo, quando as atividades mineradoras se intensificam no país, promovendo, por um lado, a mudança do eixo econômico e político e, por outro, grande deslocamento populacional para a porção Centro-Sul do país, especialmente para as então províncias de Minas Gerais e Rio de Janeiro (MARCíLIO, 1974).

A partir de então, primeiramente com a atividade mineradora e, posteriormente, com o avanço da cafeicultura, ao longo do século XIX e o início do século XX, com a industrialização, com as fronteiras agrícolas, com o desenvolvimento de diversas atividades

\footnotetext{
${ }^{1}$ A discussão sobre a articulação entre desenvolvimento econômico, expansão populacional e criação de vilas, cidades e municípios, que fundamenta o presente estudo, foi sistematizada e apresentada em Siqueira (2003).
} 
regionais e, com especial destaque, com a maior integração do mercado interno, a rede de cidades se interiorizou e se ramificou a partir de intenso processo de criação de municípios. Isso favoreceu a configuração no Brasil de uma rede de cidades descentralizada em diferentes pontos do território e composta por municípios de diferentes portes populacionais, diferenciando-o muito de outros países latino-americanos, como Argentina, Chile e Uruguai (FARIA, 1976; MARTINE e CAMARGO, 1984; CUNHA, 2003).

Com isso, pretende-se destacar que o processo de criação de municípios, ao longo de toda a trajetória de ocupação do território nacional, pode ser considerado como expressão direta da atuação de duas dimensões: o desenvolvimento econômico e a expansão da população no território. Mais recentemente, no final do século XX, esse processo emancipatório passa a assumir um novo significado: em parcela significativa de casos, deixa se ser expressão direta de um dinamismo econômico e populacional "positivo" e passa a atuar, de forma mais preponderante, uma dimensão política-institucional (SIQUEIRA, 2003).

Ou seja, ao longo dos anos de 1990, influenciado tanto pela abertura política do país quanto pelas mudanças no status político e financeiro dos municípios brasileiros, promovidas pela Constituição de 1988, assistiu-se, em todas as Unidades da Federação, a uma intensificação no processo de criação de municípios, marcadamente de pequenos municípios - o que despertou acalorado debate, na época, entre os "favoráveis" e os "contrários" ao caráter "permissivo" assumido pelo processo de criação de novos municípios, durante os 90's, onde os argumentos favoráveis ao "empoderamento" dos governos locais se contrapunham àqueles que defendiam uma maior racionalização fiscal e controle dos recursos públicos (GOMES e MACDOWELL, 2000; SERRA e AFONSO, 1999; SIQUEIRA, 2003).

O resultando disso foi a suspensão do processo de criação de municípios, em 1996, acompanhada do encaminhamento de um dos primeiros projetos de lei que visava estabelecer regras e quesitos mais rígidos - o Projeto de Lei Complementar PLP 130/1996², que tramitou por mais de dez anos no Congresso, sendo apensado, em 2008, ao PLP 416/2008, cuja origem foi o Projeto de Lei do Senado PLS 98/2002 - nesses dois últimos projetos de lei, foram incluídos critérios mais rígidos, em comparação com a legislação que amparou o processo durante a década de 1990, e diferenciados regionalmente para a

\footnotetext{
${ }^{2} \mathrm{~A}$ tramitação desses projetos de lei foi levantada no site da Câmara dos Deputados, a partir do site: http://www2.camara.leg.br/.
} 
criação de novos municípios, além de versarem também sobre o estabelecimento de procedimentos que facilitavam a fusão e incorporação municipais.

Porém, em 2013, a Presidente Dilma Rousseff vetou integralmente o Projeto de Lei do Senado 98/2002, com a justificativa de que alguns dispositivos do projeto poderiam, mais uma vez, estimular a criação de pequenos municípios pelo país, o que poderia fragmentar ainda mais a repartição do Fundo de Participação dos Municípios, prejudicando a gestão pública local.

Em reposta ao veto presidencial, o Senado encaminhou para tramitação no Congresso Nacional o PLS 104/2014, que ganhou repercussão nacional, durante o ano de 2014, com a decisão da Presidente mais uma vez vetando integralmente o projeto e adiando novamente a regulamentação da questão relativa ao processo de criação de novos municípios no país. Mais uma vez, o Senado reelaborou um projeto de lei tratando da questão - o PLS 199/2015 - que foi aprovado no Senado e precisa ser apreciado e aprovado na Câmara dos Deputados.

Se, num período mais recente, tal processo se caracteriza mais como uma expressão da dimensão política-institucional, pensado como um instrumento político que poderia proporcionar, ao mesmo tempo, uma gestão pública local mais próxima da população e estimular potencialmente um maior desenvolvimento e dinamismo em determinadas regiões, não há muito tempo, o Brasil vivenciava uma situação bastante diferente: entre 1900 e 1980, o país assistiu a um intenso processo de criação de municípios em todas as unidades da federação como expressão de diversos processos em curso no país, como, por exemplo, o intenso processo de urbanização, a intensificação da industrialização e das atividades urbanas, o êxodo rural, as fronteiras agrícolas.

Com isso, aludimos que a compreensão sobre o processo de criação de municípios se dá através do maior conhecimento das suas articulações com outros fenômenos, de natureza social, política-institucional, econômica, demográfica e territorial

Nossa contribuição será desenvolvida jogando luz sobre alguns elementos dessa articulação, de forma a sobressaltar o papel do surgimento de novas municipalidades na estruturação das redes de cidades do país e, além disso, possibilitar maior compreensão de um novo elemento, trazido mais recentemente para o debate, pelo Tribunal de Contas do Estado do 
Paraná, em cujo estudo técnico chega a sugerir a fusão de pequenos municípios como uma forma de solucionar o déficit de recursos na gestão do governo local (TCE-PR, 2015).

Por fim, nosso finalidade central é trazer de volta à cena aspectos importantes de um debate que ganhou evidência na década de 1990, mas que se encontra, atualmente, bastante esquecido, o qual procurou associar o intenso processo de criação de municípios da década de 1990 com o contexto de abertura política, descentralização políticoadministrativa do Estado, autonomia dos entes federados e incentivo à maior participação popular nas decisões públicas, cujos princípios ganharam força com a Constituição Federal de 1988.

O artigo está estruturado da seguinte forma: na sequência da seção introdutória, serão os apresentados os procedimentos de pesquisa e metodologia adotada; na terceira seção, trataremos os aspectos gerais dos processos de criação de municípios no Brasil e no Paraná; na quarta seção, o foco do estudo volta-se para as considerações dos pequenos municípios e o momento emancipatório mais recente; e, por fim, na quinta seção, são apresentadas as considerações finais do estudo.

\section{Procedimentos de pesquisa e métodos}

Para a realização desse trabalho, partimos, de um lado, do balanço da literatura, internacional e nacional, sobre o processo de criação e fusão de municípios e, por outro, da definição de um recorte empírico especifico, baseado na análise de dados selecionados sobre o estado do Paraná, com objetivo de jogar luz aos aspectos mais relevantes deste debate, no período mais contemporâneo.

Assim, partindo do balanço do debate internacional, destacamos, inicialmente, que o vínculo com a discussão desenvolvida aqui se faz a partir do que se poderia denominar por "políticas territoriais", "reformas territoriais" ou "reformas das fronteiras administrativas" (BLOM-HANSEN, 2010; EGGER et al., 2017), mais especificamente o que a literatura aponta como "fusão municipal" (municipal amalgamation, municipal mergers). 
Diferentemente do enfoque do presente trabalho, voltado para a criação de municípios (municipal secessions), diferentes estudos realizados em países desenvolvidos, como Canadá, Dinamarca, Holanda, Alemanha e Japão, apontam para a adoção, por parte do governo, de uma política de reforma de fronteiras administrativas, expressa por um amplo processo de fusão municipal, como uma medida para reduzir custos e melhorar a eficiência administrativa do Estado (BLOM-HANSEN, 2010; EGGER et al., 2017; KUSHNER e SIEGEL, 2003; BLESSE e BASKARAN, 2013; KAUDER, 2014; SWENDEN, 2006; SUZUKI e HA, 2017; SHIMIZU, 2013).

De uma forma geral, esses trabalhos compõem uma diversidade de abordagens teóricometodológicas, com diferentes tipos de investigação e apontando para avaliações diversificadas sobre a temática, não constituindo necessariamente conclusões consensuais, especialmente no que se refere ao impacto esperado por essa reforma territorial na redução dos gastos públicos e melhoria da prestação de serviços públicos - motivação principal para adoção de tal reforma por parte dos governos.

Soma-se a isso o fato de que o balanço dessas investigações apontaram para a necessidade de se considerar tais políticas de "fusão municipal" para além da dimensão orçamentária e fiscal governamental. Nesse sentido, destaca-se o estudo de Sweden (2006) que, ao analisar vários países da União Europeia, destaca que o "municipal amalgamation" pode trazer resultados imprevistos sobre o processo eleitoral e a redistribuição de poder entre as instâncias de governo, além de poder representar um impacto negativo nas identidades regionais.

Por sua vez, considerando estudos sobre a América Latina, a partir do estudo de Grindle (2009), é possível observar a existência de semelhanças entre os processos ocorridos no México e no Brasil quanto às chamadas "políticas territoriais". Assim, nos dois países verifica-se um significativo processo de criação de novos municípios num contexto marcado pelo processo de descentralização político-administrativa do Estado.

Por fim, vale ressaltar que uma análise comparativa internacional dessa temática apresenta desafios que não podem ser negligenciados. Nesse sentido, destaca-se que a análise de "reformas territoriais" são influenciadas pelo tipo de organização federativa do país, o papel político desempenhado pelos municípios, o procedimento de criar ou fundir municípios, o sistema eleitoral, o caráter voluntário ou compulsório da reforma territorial, o porte 
populacional dos municípios envolvidos, entre outros - o que faz com que tenhamos bastante cuidado com qualquer possível semelhança entre os países.

Já a produção brasileira sobre a temática assume diferentes feições. Primeiramente, o processo de "alterações territoriais" que o Brasil assistiu, ao longo da década da 1990 e início dos anos 2000, foi um intenso processo de criação de novos municípios, a partir de desmembramentos territoriais. Em segundo lugar, os estudos se concentraram nas áreas de Ciência Política, Administração, Geografia e Economia, cujo balanço pode ser encontrado em Siqueira (2003) e Tomio (2002). Por fim, vale destacar o debate sobre o processo de criação de municípios dos anos 1990 assistiu a uma marcada polarização entre os "contrários ao processo", que viam nele um ônus a mais ao Estado, e os "defensores do processo", que o associavam ao espírito da abertura política do país, à descentralização política e à maior possibilidade de participação popular.

Em geral, esses estudos apresentaram uma diversidade de metodologias e fontes de dados, compreendendo desde análises de cunho orçamentário e fiscal, como análises políticainstitucionais, demográficas e geográficas, envolvendo abordagens tanto quantitativas como qualitativas.

Em termos de análises de caráter mais qualitativo, podemos destacar o estudo de Tomio (2002), que se focou em analisar a tramitação legislativa dos processos de criação de municípios nas Assembleias Legislativas Estaduais. Por sua vez, em sua pesquisa de mestrado, Siqueira (2003) realiza uma análise documental e comparativa das diferentes constituições federais do país, procurando destacar as diferentes formas assumidas pela dimensão político-institucional do processo de criação de municípios no país.

Para a realização do presente trabalho, porém, optou-se por uma abordagem de caráter mais quantitativo, baseado no estudo empírico da análise dos dados sobre a população e municípios criados no Brasil e no estado do Paraná, entre 1900 e 2010. Além disso, para as mesorregiões paranaenses, foram levantados também os dados o IDH-M de 2000 e 2010.

\section{Processo de criação de municípios no Brasil: aspectos} demográficos e urbanos

Partimos da consideração de que o processo de criação de municípios esteve vinculada a diferentes processos econômicos, demográficos, políticos e sociais desde o início do 
processo de ocupação e domínio territorial do país - contribuindo para a descentralização e heterogeneidade do sistema urbano brasileiro.

Nesse sentido, embora não seja nosso objetivo esgotar o diversificado debate sobre o processo de urbanização no Brasil, destacamos duas referências que corroboram nosso argumento. Assim, nas análises sobre a expansão do sistema urbano brasileiro, feitas por Faria (1976), é possível visualizar aspectos que ainda persistem no sistema urbano: a articulação entre diferentes processos como o desenvolvimento e a expansão das atividades econômicas nas diferentes regiões do país, a redistribuição da população no território nacional e a rede de cidades estruturada em diferentes momentos da história econômica, social e política do país.

Esse diversidade do processo de urbanização do Brasil também é abordada numa análise comparativa, também historicamente datada, mas com relevância para o momento atual, realizada por Cano (1989), no qual, ao comparar os processos de urbanização na Europa, Estados Unidos e países latino-americanos, o autor destaca a necessidade de se considerar a articulação entre as atividades agrícolas e os demais setores de atividades na configuração da rede de cidades nas diferentes regiões do país.

Estabelecidos esses referenciais, passaremos para a nossa análise. Apresentamos na tabela 1 a evolução do número de municípios criados em todas as unidades da federação, desde o início do século XX:

\begin{tabular}{|c|c|c|c|c|c|c|c|c|c|c|}
\hline Regiões & 1900 & 1920 & 1940 & 1950 & 1960 & 1970 & 1980 & 1990 & 2000 & 2010 \\
\hline Nordeste & 386 & 417 & 573 & 608 & 927 & $\begin{array}{r}1.37 \\
6\end{array}$ & 1.377 & 1.515 & 1.794 & 1.794 \\
\hline Sudeste & 344 & 433 & 639 & 850 & $\begin{array}{r}1.09 \\
3\end{array}$ & $\begin{array}{r}1.41 \\
0\end{array}$ & 1.412 & 1.437 & 1.668 & 1.668 \\
\hline Sul & 109 & 136 & 179 & 224 & 415 & 717 & 725 & 874 & 1.188 & 1.191 \\
\hline $\begin{array}{l}\text { Centro- } \\
\text { Oeste }\end{array}$ & 37 & 53 & 69 & 100 & 210 & 254 & 280 & 380 & 463 & 467 \\
\hline Norte & 58 & 72 & 99 & 112 & 154 & 200 & 210 & 298 & 449 & 450 \\
\hline BRASIL & 934 & 1.111 & $\begin{array}{r}1.55 \\
9\end{array}$ & 1.894 & $\begin{array}{r}2.79 \\
9\end{array}$ & $\begin{array}{r}3.95 \\
7\end{array}$ & 4.004 & 4.504 & 5.562 & 5.570 \\
\hline
\end{tabular}

Tabela 1: Número de municípios existentes, por Grandes Regiões do país, $1900-2010$

Fonte de dados: Divisão Territorial Brasileira, IBGE

* Para o levantamento de número de municípios, os dados referem-se à data de "criação" do município" e não à de "instalação". 
O processo de criação no Brasil, entre os anos de 1900 e 2010, passou de 934 a 5.570 municípios, crescendo com mais intensidade neste último século de nossa história - ao longo do qual esse número multiplicou-se por seis -, do que nos trezentos anos anteriores.

O mapa 1 apresenta as Grandes Regiões do Brasil, acompanhadas de suas respectivas informações censitárias relativas ao tamanho populacional e quantidade de municípios, em 2010.

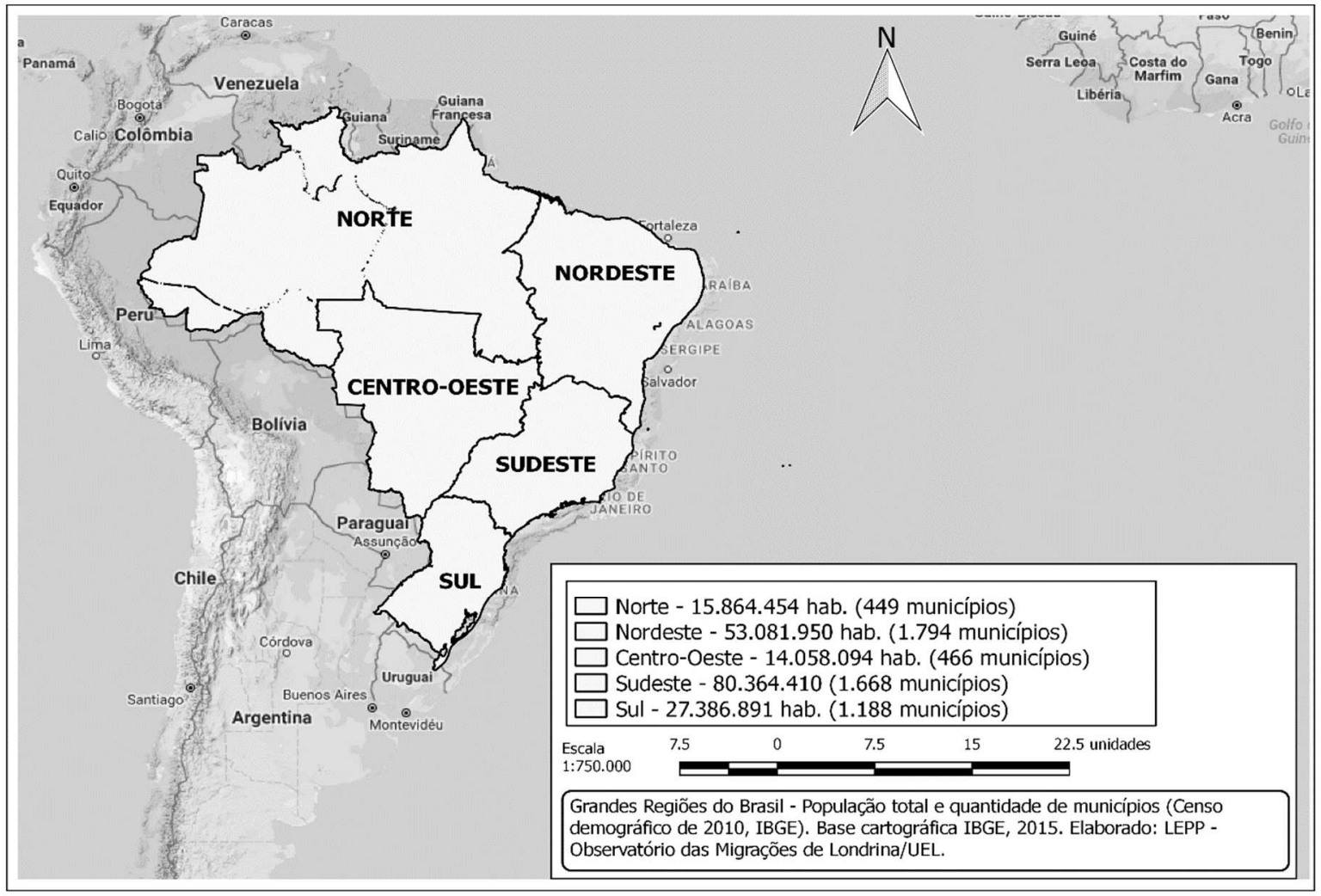

Mapa 1: Grandes Regiões do Brasil, população total e número de municípios, 2010 Fonte de dados: Censo Demográfico 2010, IBGE; Base cartográfica, IBGE, 2015. [Elaboração própria]

A partir do gráfico 1, visualiza-se mais claramente a intensidade com que se processou a criação de municípios nas diferentes regiões do país, no período considerado. Nota-se que, em 1900, as regiões Nordeste e Sudeste concentravam os maiores números de municípios e continuam sendo as regiões com maior número de municipalidades, em 2010, com leve predomínio da região Nordeste. Destaca-se ainda que esse processo assume uma inclinação importante a partir de 1940, mantendo um crescimento constante até a década de 1970. 


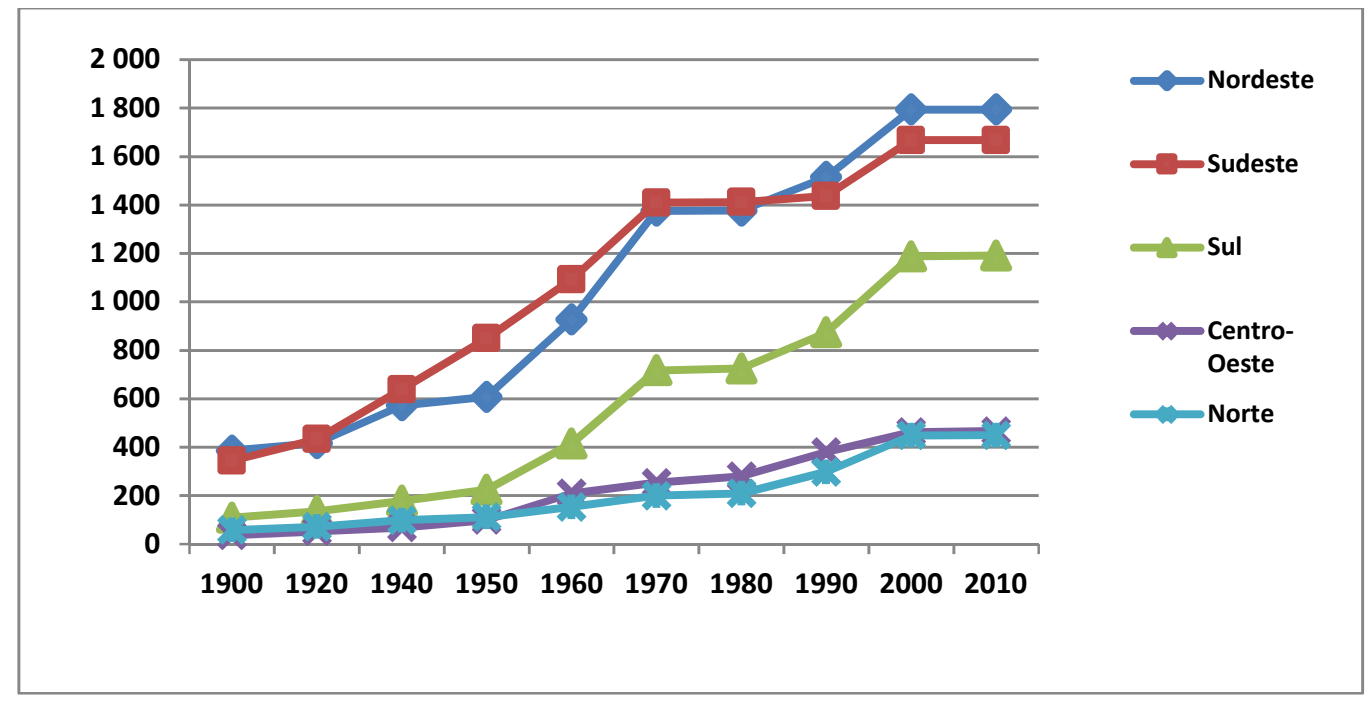

Gráfico 1: Evolução do número de municípios, por Grandes Regiões 1900-2010

Fonte: Divisão Territorial Brasileira (DTB), IBGE

No outro extremo, encontram-se as regiões Centro-Oeste e Norte que, em 1900, possuíam menos de 100 municípios. Nelas, o número de municípios criados seguiu a mesma tendência das demais regiões, com intensificação entre os anos de 1950 e 1970, porem mantendo-se num patamar menor em termos de quantidade de municípios, no período mais recente.

Destaca-se, ainda, a evolução peculiar vivenciada pela região Sul nesse processo. Em 1900, a região possuía um pouco mais de 100 municípios e, nas décadas seguintes, passou por um crescimento lento no número de municípios, sendo que esse processo se intensifica entre os anos de 1950 e 1970. Em seguida, acontece um arrefecimento no ritmo de criação de municípios, que volta a apresentar um grande impulso ao longo dos anos de 1990. O resultado disso é que a região Sul se situa na terceira posição entre as regiões com maior número de municípios, em 2010, distanciando-se das regiões Centro-Oeste e Norte. 


\begin{tabular}{llllllllll}
\hline Regiões & $\mathbf{1 9 0 0 -}$ & $\mathbf{1 9 2 0}-$ & $\mathbf{1 9 4 0 -}$ & $\mathbf{1 9 5 0 -}$ & $\mathbf{1 9 6 0 -}$ & $\mathbf{1 9 7 0}-$ & $\mathbf{1 9 8 0}-$ & $\mathbf{1 9 9 0 -}$ & $\mathbf{2 0 0 0 -}$ \\
& $\mathbf{1 9 2 0}$ & $\mathbf{1 9 4 0}$ & $\mathbf{1 9 5 0}$ & $\mathbf{1 9 6 0}$ & $\mathbf{1 9 7 0}$ & $\mathbf{1 9 8 0}$ & $\mathbf{1 9 9 0}$ & $\mathbf{2 0 0 0}$ & $\mathbf{2 0 1 0}$ \\
\hline Nordeste & 0,39 & 1,60 & 0,59 & 4,31 & 4,03 & 0,01 & 0,96 & 1,70 & 0,00 \\
Sudeste & 1,16 & 1,96 & 2,89 & 2,55 & 2,58 & 0,01 & 0,18 & 1,50 & 0,00 \\
Sul & 1,11 & 1,38 & 2,27 & 6,36 & 5,62 & 0,11 & 1,89 & 3,12 & 0,03 \\
Centro-Oeste & 1,81 & 1,33 & 3,78 & 7,70 & 1,92 & 0,98 & 3,10 & 2,00 & 0,09 \\
Norte & 1,09 & 1,61 & 1,24 & 3,24 & 2,65 & 0,49 & 3,56 & 4,18 & 0,02 \\
\hline \multicolumn{1}{c}{ BRASIL } & $\mathbf{0 , 8 7}$ & $\mathbf{1 , 7 1}$ & $\mathbf{1 , 9 7}$ & $\mathbf{3 , 9 8}$ & $\mathbf{3 , 5 2}$ & $\mathbf{0 , 1 2}$ & $\mathbf{1 , 1 8}$ & $\mathbf{2 , 1 3}$ & $\mathbf{0 , 0 1}$ \\
\hline
\end{tabular}

Tabela 2: Taxa de crescimento anual dos municípios existentes, por Grandes Regiões 1900-2010

Fonte de dados: Divisão Territorial Brasileira, IBGE [Elaboração própria]

Para complementar esse quadro, vemos, a partir das taxas de crescimento anual dos municípios nas grandes regiões do país, que os momentos de maior ritmo no aumento no número de municípios no país são as décadas de 1950 e 1960, marcadas também pelo intenso processo de urbanização do país, de êxodo rural e de expansão da fronteira na região Sul. Outro momento de elevado ritmo de criação de municípios é o da década de 1990, quando ocorre uma proliferação de pequenos municípios por todo país.

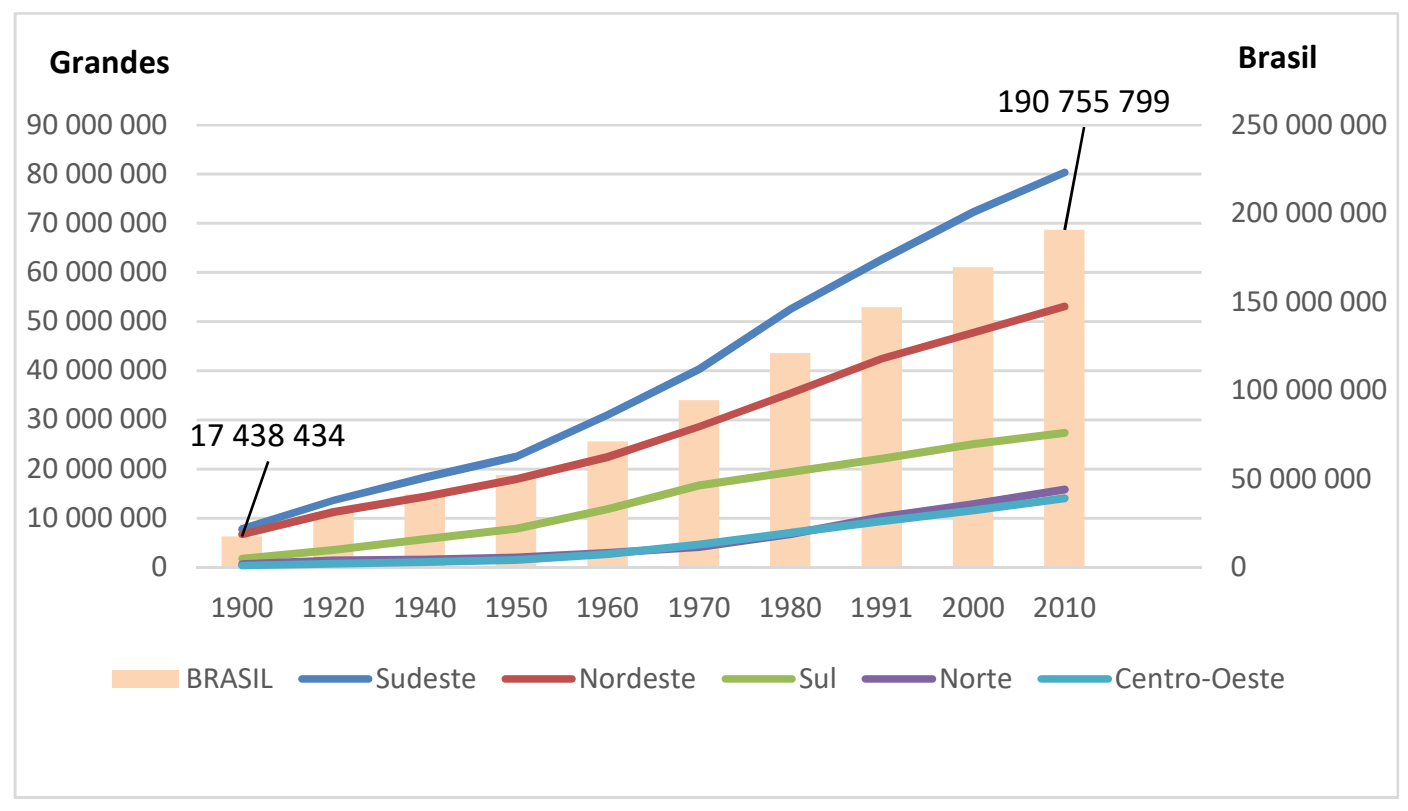

Gráfico 2: População total, Brasil e Grandes Regiões, 1900-2010

Fonte de dados: Censos demográficos, Brasil, 1900-2010 [IBGE]

Subjacente a esse processo de criação de municípios, encontra-se a atuação, como já destacado anteriormente, de fatores demográficos, econômicos e político-institucionais, os 
quais, em cada momento, vão contribuir de forma específica na configuração desse processo. Considerando a dimensão demográfica, apoiado no gráfico 2, observamos que o período de 1900 a 2010 correspondeu a um grande crescimento da população brasileira que passou de 17,4 milhões, em 1900, para mais de 190 milhões, em 2010 - ou seja, a população cresceu onze vezes em 110 anos. Em termos regionais, destacam-se o sudeste e o nordeste como as regiões mais populosas, e a região sul como a terceira mais populosa no país.

Esse período de um século compreende mudanças significativas na dinâmica demográfica brasileira. Primeiramente, destaca-se, a partir de 1940, o início da queda da mortalidade geral no Brasil, acompanhada do aumento da expectativa de vida, e, paralelamente, a manutenção de altos níveis de fecundidade. É a atuação desses dois processos que vai contribuir para o elevado crescimento demográfico, verificado até 1970 , em função do crescimento vegetativo pregresso da população. A partir de então, o Brasil inicia a sua transição demográfica, começando a registrar níveis decrescentes de fecundidade (CARVALHO, 2004).

Porém, mesmo vivenciando taxas cada vez menores de fecundidade, entre 1970 e 2010, o Brasil registra um ganho de quase 100 milhões de pessoas, o que vai impactar diretamente, entre outras coisas, na sua redistribuição espacial da população, na rede de cidades e na sua transição urbana.

Consideramos esse aspecto da urbanização, temos que, embora a transição urbana seja algo quase inexorável, esse processo não acontece no mesmo ritmo e nem com o mesmo significado nas diferentes regiões do país. 


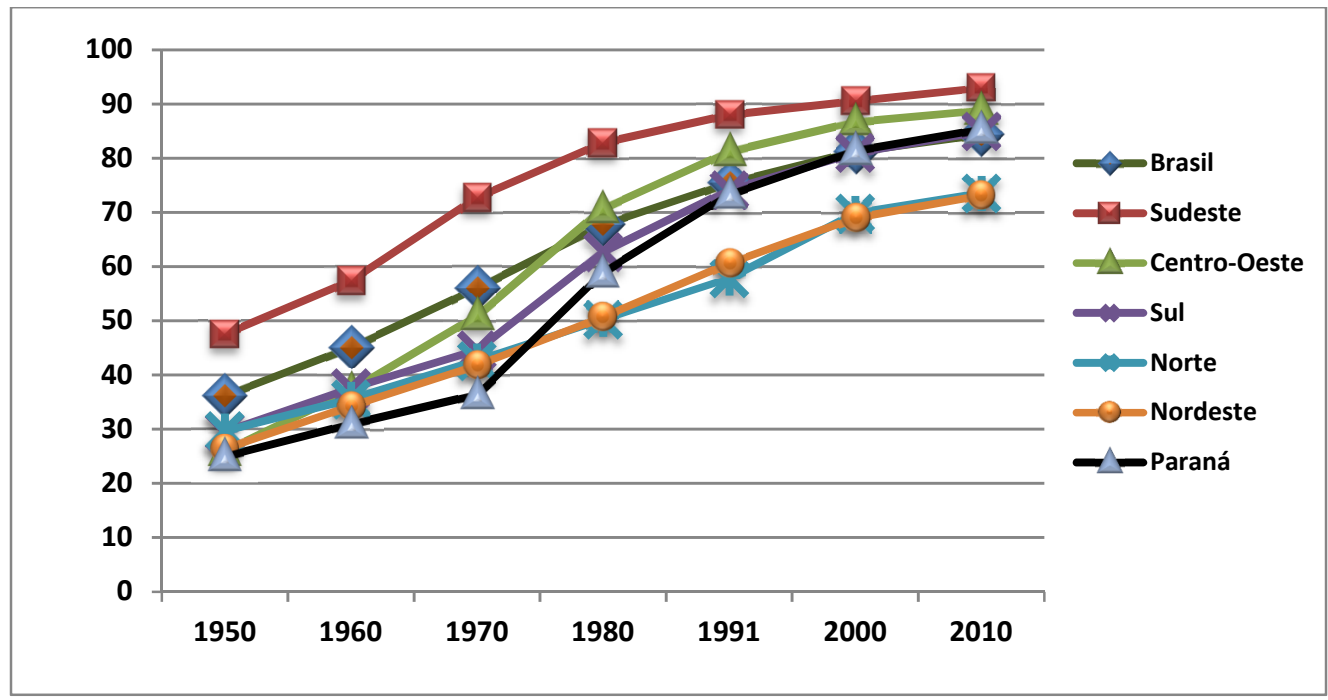

Gráfico 3: População urbana (\%), Brasil, Grandes regiões e estado do Paraná 1950-2010

Fonte de dados: Censos demográficos, IBGE

Assim, enquanto o Brasil registrava pela primeira o predomínio da população vivendo em áreas urbanas (56\%) em 1970, o Sudeste já havia ultrapassado essa marca uma década antes, apresentando cerca de $57 \%$ de urbanização. Por sua vez, o Centro-Oeste acompanha o padrão nacional e também registra mais da metade da sua população vivendo nas áreas urbanas, em 1970.

Fechando o quadro, temos as regiões Sul, Norte e Nordeste que, em 1970, ainda possuíam predomínio da população vivendo em áreas rurais, sendo que somente em 1980, elas passam, também, a apresentar predomínio da população urbana.

Neste cenário, em função do objetivo deste trabalho, destacamos a evolução da urbanização no estado do Paraná. Nesse sentido, observa-se que, enquanto a Região Sul apresentava um nível de urbanização de 44,5\%, em 1970, o estado do Paraná registrava $36 \%$ da sua população em áreas rurais - isso significa que o elevado processo de criação de municípios paranaenses, apontado anteriormente, ocorreu num contexto de grande concentração de pessoas vivendo em áreas rurais.

Num balanço final dessa seção, destaca-se que, durante as décadas de 1950 a 1970, em todas as unidades da federação, registrou-se maior crescimento no número de municípios criados, acompanhado de um maior incremento populacional e de um processo de urbanização acelerado e heterogêneo. 
No entanto, se um maior incremento foi observado em todas as unidades federativas, o seu significado assume contornos específicos, nos diferentes estados brasileiros. Pois, ao mesmo tempo em que o Sudeste assistia a um intenso fluxo imigratório, proveniente principalmente da Região Nordeste do país, para as suas principais metrópoles, os estados do Nordeste vivenciavam um importante êxodo rural e reconhecido processo emigratório para o Sudeste do país.

Com isso, destaca-se que o processo de urbanização no Brasil apresenta diversidades expressivas. Assim, em 1950, enquanto o Brasil possuía $64 \%$ da sua população vivendo em áreas rurais, entre as UF's registrava-se uma grande discrepância, tendo o estado do Piauí, por exemplo, $84 \%$ da sua população vivendo em áreas rurais, contrastando com o Rio de Janeiro, que possuía apenas $27 \%$ nessa situação, constituindo-se no estado mais urbanizado, e com alto nível de urbanização, já na metade do século XX.

Na Região Sul, por sua vez, os três estados possuíam uma proporção de população rural acima da média nacional. Em 1950, a proporção de população rural no Rio Grande do Sul era de $66 \%$, em Santa Catarina, era de 76,8\% e, no Paraná, cerca de 75\% dos seus habitantes viviam em áreas rurais.

Especificamente com relação ao estado do Paraná, tem-se que uma situação caracterizada pelo baixo grau de urbanização, um elevado processo de crescimento populacional e aumento expressivo na quantidade de municípios criados está diretamente vinculada ao auge da sua fronteira agrícola, baseada nas pequenas e médias propriedades, estimulada pela expansão da cafeicultura, especialmente na porção norte do estado, reforçando aqui os argumentos apresentados por Cano (1989), na sua análise da urbanização da região sul do país, na qual o autor destaca a importância das atividades agrícolas no desenvolvimento e consolidação da rede de cidades do estado.

Tomando como o foco a urbanização, mais especificamente a "transição urbana", que se refere, basicamente, à passagem da uma situação predominantemente rural para outra, onde a população residente em áreas urbanas torna-se maioria em comparação com as áreas rurais (Martine e McGranahan, 2010), temos que, enquanto o país, no censo demográfico de 1970, pela primeira vez registrou uma população urbana superior à população rural (população urbana correspondia a $56 \%$ do total da população total), 
somente na década subsequente, em 1980, o estado do Paraná vivenciaria sua transição urbana, alcançando o nível de 59\% de sua população residindo em áreas urbanas.

\subsection{Criação de municípios nas mesorregiões do Paraná}

No estado do Paraná, a criação de novas municipalidades seguiu esse mesmo padrão, com intensidade concentrada nos anos 40, 50 e 60 do século XX. Considerando, de acordo com Martine e Camargo (1984), que esse período correspondeu ao auge da fronteira agrícola do Paraná e que a sua ocupação territorial e expansão populacional decorrentes se realizaram, por um lado, através da atuação de uma empresa privada de colonização e, por outro, do estímulo à pequena e média propriedades rurais, tem-se uma peculiaridade do processo de criação de municípios paranaenses entre 1940 e 1970: ele se realizou concomitantemente à fronteira agrícola do Paraná.

Ou seja, a fronteira agrícola paranaense, ao mesmo tempo em que resultou num alto crescimento populacional - principalmente da rural - no estado, ela foi concomitante a um intenso processo de criação de novos municípios.

O estado do Paraná pode ser analisado considerando-se a divisão longitudinal do seu território, a partir da qual duas porções definem-se claramente: a porção norte, que inclui as mesorregiões de ocupação mais recente, iniciada, principalmente, a partir das décadas de 1920 e 1930, e vinculada à expansão da cafeicultura no território paranaense. Por outro lado, a porção sul, de ocupação mais antiga, compreendendo a capital estadual e a porção litorânea (IPARDES, 2004; ROLIM, 1995).

Argumenta-se, aqui, que essas duas porções territoriais, por possuírem diferentes históricos de ocupação territorial e desenvolvimento econômico, apresentariam também diferentes dinâmicas demográficas, migratórias e de criação de municípios.

Na tabela 3, estão os dados de população das diferentes mesorregiões paranaenses, divididas nas duas porções que dividem o estado, para o período de 1950 a 2010, a partir da qual se destaca o maior peso populacional das mesorregiões da porção norte do território, em 1960 e 1970 - expressão direta dos grandes fluxos migratórios que adentraram o estado, a partir da década de 1940, em função da fronteira agrícola do Paraná. 


\begin{tabular}{lrrrrrrr}
\hline Mesorregiões & \multicolumn{1}{c}{1950} & \multicolumn{1}{c}{1960} & \multicolumn{1}{c}{1970} & 1980 & 1991 & 2000 & 2010 \\
\hline Norte Central & 517.595 & 1.129 .553 & 1.521 .540 & 1.459 .566 & 1.638 .677 & 1.829 .068 & 2.037 .183 \\
Norte Pioneiro & 423.744 & 608.559 & 705.953 & 571.713 & 555.339 & 548.190 & 546.224 \\
Noroeste & 0 & 512.758 & 962.778 & 746.543 & 655.509 & 641.084 & 678.319 \\
Centro Ocidental & 32.948 & 230.971 & 528.734 & 406.734 & 387.451 & 346.648 & 334.125 \\
\hline Porção Norte & $\mathbf{9 7 4 . 2 8 7}$ & $\mathbf{2 . 4 8 1 . 8 4 1}$ & $\mathbf{3 . 7 1 9 . 0 0 5}$ & $\mathbf{3 . 1 8 4 . 5 5 6}$ & $\mathbf{3 . 2 3 6 . 9 7 6}$ & $\mathbf{3 . 3 6 4 . 9 9 0}$ & $\mathbf{3 . 5 9 5 . 8 5 1}$ \\
\hline Metropolitana Curitiba & 455.292 & 694.155 & 1.050 .805 & 1.703 .819 & 2.319 .526 & 3.053 .313 & 3.493 .742 \\
Centro Oriental & 216.751 & 253.742 & 355.253 & 472.655 & 547.559 & 623.356 & 689.279 \\
Oeste & 16.421 & 135.036 & 752.432 & 960.775 & 1.016 .481 & 1.138 .582 & 1.219 .558 \\
Centro-Sul & 245.458 & 242.638 & 338.136 & 484.245 & 501.428 & 533.317 & 544.190 \\
Sudeste & 207.338 & 222.908 & 267.830 & 302.530 & 348.617 & 377.274 & 404.779 \\
Sudoeste & 0 & 212.628 & 446.360 & 521.269 & 478.126 & 472.626 & 497.127 \\
\hline Porção Sul & $\mathbf{1 . 1 4 1 . 2 6 0}$ & $\mathbf{1 . 7 6 1 . 1 0 7}$ & $\mathbf{3 . 2 1 0 . 8 1 6}$ & $\mathbf{4 . 4 4 5 . 2 9 3}$ & $\mathbf{5 . 2 1 1 . 7 3 7}$ & $\mathbf{6 . 1 9 8 . 4 6 8}$ & $\mathbf{6 . 8 4 8 . 6 7 5}$ \\
\hline PARANÁ & $\mathbf{2 . 1 1 5 . 5 4 7}$ & $\mathbf{4 . 2 4 2 . 9 4 8}$ & $\mathbf{6 . 9 2 9 . 8 2 1}$ & $\mathbf{7 . 6 2 9 . 8 4 9}$ & $\mathbf{8 . 4 4 8 . 7 1 3}$ & $\mathbf{9 . 5 6 3 . 4 5 8}$ & $\mathbf{1 0 . 4 4 4 . 5 2 6}$ \\
\hline
\end{tabular}

Tabela 3: População residente total do estado Paraná, por Mesorregiões 1950-2010

Fonte de dados: Censos demográficos de 1950 a 2010, IBGE

O impacto da cafeicultura, da colonização e do desenvolvimento regional para o conjunto do estado, no contexto de expansão da fronteira agrícola paranaense, não se restringiu às suas dimensões demográficas e econômicas. Foi durante essa década também que se conclui importante eixo rodoviário - a Rodovia do Café - que liga o norte do estado ao porto de Paranaguá, que se tornou importante meio de escoamento da produção cafeeira.

Destaca-se que esse projeto de interligação rodoviária, inclusive interestadual e intercontinental, já existia desde a época imperial, porém foi nesse momento de grande dinamismo econômico e populacional do Paraná, entre 1950 e 1970, que o projeto é realizado, financiado com recursos do Fundo de Desenvolvimento Econômico e do Banco Interamericano de Desenvolvimento (BID) e com a decisiva intervenção do presidente dos Estados Unidos, John Kennedy ${ }^{3}$, que via nesta rodovia importante eixo de integração continental.

Os impactos dessa preponderância demográfica e econômica da porção norte do estado, nas décadas de 1960 e 1970, foi sentido também no peso político que desempenhado pela

\footnotetext{
3 Informações retiradas do site do Departamento de Estradas de Rodagem, do Paraná: <http://www.der.pr.gov.br/>.
} 
região nesse momento, pois além esse maior peso populacional se traduzia também em maior peso eleitoral, tornando o voto da os eleitores da região decisivo na definição do governo (MAGALHÃES, 2001).

\begin{tabular}{lcccccc}
\hline Mesorregiões & $\mathbf{1 9 5 0 - 1 9 6 0}$ & $\mathbf{1 9 6 0 - 1 9 7 0}$ & $\mathbf{1 9 7 0 - 1 9 8 0}$ & $\mathbf{1 9 8 0 - 1 9 9 1}$ & $\mathbf{1 9 9 1 - 2 0 0 0}$ & $\mathbf{2 0 0 0 - 2 0 1 0}$ \\
\hline Norte Central & 8,12 & 3,02 & $-0,41$ & 1,06 & 1,23 & 1,08 \\
Norte Pioneiro & 3,69 & 1,50 & $-2,09$ & $-0,26$ & $-0,14$ & $-0,04$ \\
Noroeste & 0 & 6,50 & $-2,51$ & $-1,18$ & $-0,25$ & 0,57 \\
Centro Ocidental & 21,50 & 8,63 & $-2,59$ & $-0,44$ & $-1,23$ & $-0,37$ \\
\hline Porção Norte & $\mathbf{9 , 8 0}$ & $\mathbf{4 , 1 3}$ & $\mathbf{- 1 , 5 4}$ & $\mathbf{0 , 1 5}$ & $\mathbf{0 , 4 3}$ & $\mathbf{0 , 6 7}$ \\
\hline Metropolitana & & & & & & \\
Curitiba & 4,31 & 4,23 & 4,95 & 2,84 & 3,10 & 1,36 \\
Centro Oriental & 1,59 & 3,42 & 2,90 & 1,35 & 1,45 & 1,01 \\
Oeste & 23,45 & 18,74 & 2,47 & 0,51 & 1,27 & 0,69 \\
Centro-Sul & $-0,12$ & 3,37 & 3,66 & 0,32 & 0,69 & 0,20 \\
Sudeste & 0,73 & 1,85 & 1,23 & 1,30 & 0,88 & 0,71 \\
Sudoeste & 0 & $\mathbf{7 , 7 0}$ & 1,56 & $-0,78$ & $-0,13$ & 0,51 \\
\hline Porção Sul & $\mathbf{4 , 4 3}$ & $\mathbf{6 , 1 9}$ & $\mathbf{3 , 3 1}$ & $\mathbf{1 , 4 6}$ & $\mathbf{1 , 9 5}$ & $\mathbf{1 , 0 0}$ \\
\hline PARANÁ & $\mathbf{7 , 2 1}$ & $\mathbf{5 , 0 3}$ & $\mathbf{0 , 9 7}$ & $\mathbf{0 , 9 3}$ & $\mathbf{1 , 3 9}$ & $\mathbf{0 , 8 9}$ \\
\hline
\end{tabular}

Tabela 4: Taxa de crescimento anual (a.a.) da população Paraná, por Mesorregiões - 1950-2010 Fonte de dados: Censos demográficos de 1950 a 2010, IBGE

Analisando as taxas de crescimento anual da população das mesorregiões paranaenses (tabela 4), observamos que, na porção norte do estado, as regiões Centro-Ocidental e a Norte Central lideraram o crescimento populacional da porção norte, nos anos 60 , com taxas de 21,5\%a.a. e 8,1\%a.a., respectivamente. Na década de 1970, o crescimento populacional da porção norte inverte-se, em relação à porção sul, e duas mesorregiões crescem acima da média do estado: Centro-Ocidental (8,6\%a.a.) e Noroeste (6,5\%a.a.).

Por sua vez, na porção sul, a única mesorregião a apresentar crescimento populacional acima da média estadual é a Oeste, cuja ocupação territorial e expansão demográfica estão vinculadas à migração de gaúchos e catarinenses, voltados à produção da erva-mate e às atividades extrativistas, como a da madeira (IPARDES, 2004).

Por fim, destaca-se que, a partir da década seguinte, assiste-se a uma inversão nas taxas de crescimento populacional, tendo as mesorregiões da porção sul, no ano de 1970, concentrado os índices de crescimento populacional positivo do estado. Nesse mesmo ano, 
todas as mesorregiões da porção norte registraram taxas de crescimento negativo, expressando a perda populacional ocorrida em função da crise e do esgotamento da fronteira agrícola do Paraná. Simultaneamente, o estado começa a vivenciar uma mudança no eixo econômico, a partir da qual o estado passa a concentrar seus investimentos em atividades industriais e urbanas, principalmente na área compreendida pela mesorregião Metropolitana de Curitiba (IPARDES, 2004).

Nas três décadas seguintes, o estado do Paraná passa a apresentar oscilações nas suas taxas de crescimento populacional, embora elas permaneçam positivas ao longo do período. Embora esse aspecto da dinâmica demográfica e econômica não seja o objeto deste trabalho, o que deverá ser abordado em estudos posteriores, vale destacar que as mudanças que se verificam na dinâmica demográfica e migratória relacionam-se com mudanças no plano econômico, tanto no cenário nacional como no estadual, expressas pela mudança de eixo nas atividades produtivas dos estados, a crise econômica dos anos 80, a reestruturação produtiva e a desconcentração industrial a partir de São Paulo (PACHECO e PATARRA, 1997)

Voltando ao nosso recorte de análise, na tabela 5 , encontram-se o número de municípios existentes, nas mesorregiões do Paraná, no período de 1900 a 2010.

Observa-se que, no início do período, em 1900, a porção sul do estado concentrava praticamente todos os municípios paranaenses, contrastando com um único município criado na mesorregião Norte Pioneiro, localizado na porção norte do estado. 


\begin{tabular}{lrrrrrrrrrr}
\hline Mesorregiões & 1900 & $\mathbf{1 9 2 0}$ & $\mathbf{1 9 4 0}$ & $\mathbf{1 9 5 0}$ & $\mathbf{1 9 6 0}$ & $\mathbf{1 9 7 0}$ & $\mathbf{1 9 8 0}$ & $\mathbf{1 9 9 0}$ & $\mathbf{2 0 0 0}$ & $\mathbf{2 0 1 0}$ \\
\hline Norte Central & 0 & 0 & 2 & 11 & 42 & 63 & 64 & 68 & 79 & 79 \\
Noroeste & 0 & 0 & 0 & 0 & 18 & 50 & 52 & 54 & 61 & 61 \\
Norte Pioneiro & 1 & 5 & 11 & 24 & 33 & 44 & 44 & 45 & 46 & 46 \\
Centro-Ocidental & 0 & 0 & 0 & 1 & 6 & 18 & 18 & 22 & 25 & 25 \\
\hline Porção Norte & $\mathbf{1}$ & $\mathbf{5}$ & $\mathbf{1 3}$ & $\mathbf{3 6}$ & $\mathbf{9 9}$ & $\mathbf{1 7 5}$ & $\mathbf{1 7 8}$ & $\mathbf{1 8 9}$ & $\mathbf{2 1 1}$ & $\mathbf{2 1 1}$ \\
\hline Metrop. Curitiba & 11 & 11 & 12 & 18 & 21 & 30 & 30 & 30 & 37 & 37 \\
Sudoeste & 0 & 0 & 0 & 0 & 7 & 24 & 25 & 27 & 37 & 37 \\
Centro-Sul & 2 & 2 & 2 & 6 & 6 & 10 & 10 & 12 & 29 & 29 \\
Oeste & 0 & 1 & 1 & 1 & 5 & 19 & 23 & 36 & 50 & 50 \\
Sudeste & 4 & 10 & 11 & 11 & 14 & 19 & 19 & 19 & 21 & 21 \\
Centro-Oriental & 6 & 6 & 8 & 8 & 10 & 11 & 11 & 11 & 14 & 14 \\
\hline Porção Sul & $\mathbf{2 3}$ & $\mathbf{3 0}$ & $\mathbf{3 4}$ & $\mathbf{4 4}$ & $\mathbf{6 3}$ & $\mathbf{1 1 3}$ & $\mathbf{1 1 8}$ & $\mathbf{1 3 5}$ & $\mathbf{1 8 8}$ & $\mathbf{1 8 8}$ \\
\hline PARANÁ & $\mathbf{2 4}$ & $\mathbf{3 5}$ & $\mathbf{4 7}$ & $\mathbf{8 0}$ & $\mathbf{1 6 2}$ & $\mathbf{2 8 8}$ & $\mathbf{2 9 6}$ & $\mathbf{3 2 4}$ & $\mathbf{3 9 9}$ & $\mathbf{3 9 9}$ \\
\hline
\end{tabular}

Tabela 5: Número de municípios existentes - Mesorregiões do Paraná, 1900 a 2010

Fonte de dados: Divisão Territorial Brasileira, IBGE

* Para o levantamento de número de municípios, os dados referem-se à data de "criação" do município" e não à de "instalação".

Porém, essa inexistência de municípios na porção norte não significava necessariamente um vazio demográfico no território. Basta destacar que, nas áreas limítrofes ao estado de São Paulo, já havia assentamentos de paulistas que circularam pelas terras paranaenses, estabelecendo seus primeiros sítios de subsistência na segunda metade do século XIX. Além disso, a porção oeste e noroeste e norte ainda não tivesse registrado a ocupação do elemento europeu, suas terras constituíam no espaço de vida de diversas tribos indígenas.

Entre os anos de 1940 e 1970, observa-se que o número de municípios cresce significativamente nas duas porções do estado, porém, argumenta-se que, em cada uma delas, esse processo assumirá significados distintos, pois esteve vinculado à forma de ocupação territorial e populacional própria de cada porção. Assim, enquanto na porção sul, a criação de novos municípios vinculou-se a uma diversidade de atividades econômicas, como o extrativismo, a agricultura familiar, a produção da erva-mate, comércio e serviços, na porção norte, a criação de novos municípios acompanhou a expansão da cafeicultura e das atividades que davam suporte à atividade cafeeira.

No entanto, mesmo com esses fatores que caracterizam a dinâmica econômica e demográfica das duas porções territoriais do estado, as mesorregiões não apresentaram o 
mesmo padrão de criação de municípios - o que reforça outro argumento desse trabalho de que o processo de criação de municípios é tridimensional, sendo definido não somente pela dimensão econômica e demográfica, mas também pela política-institucional.

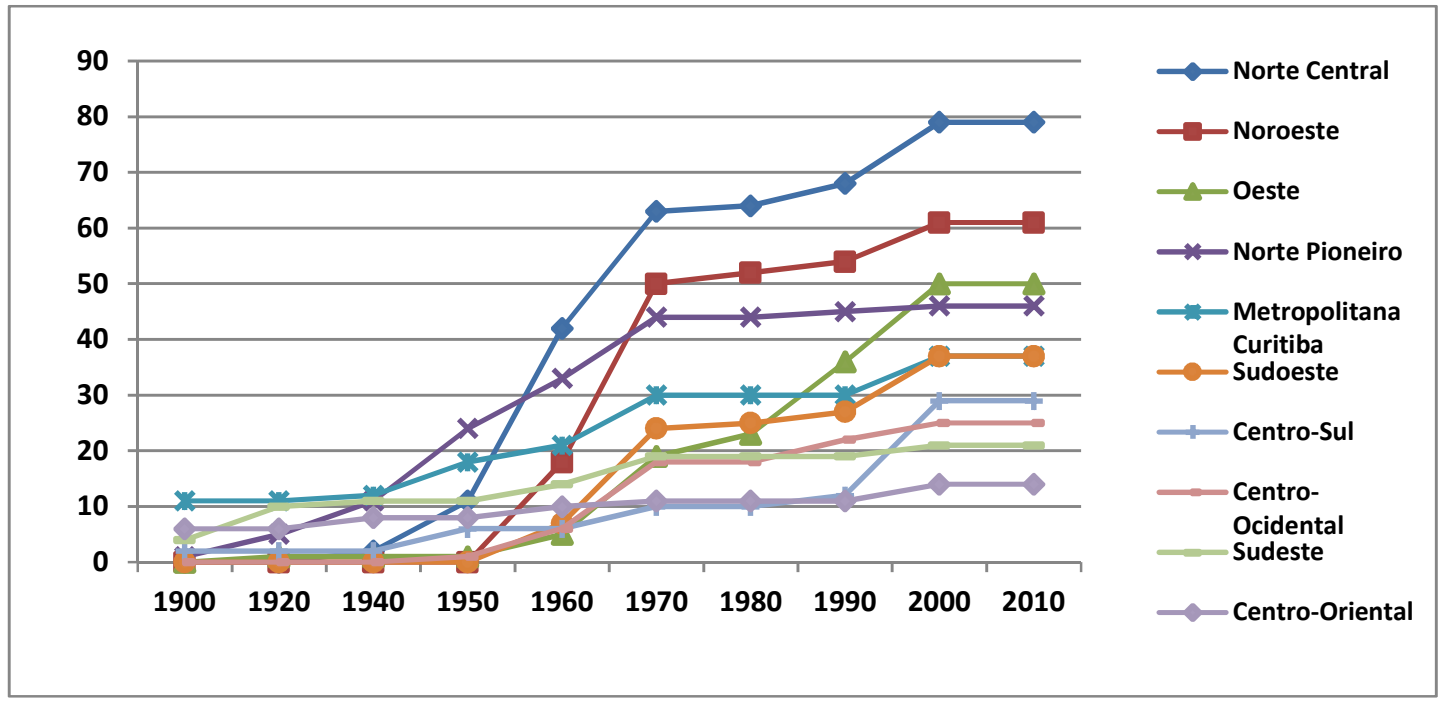

Gráfico 4: Número de municípios existentes, Mesorregiões do Paraná, 1900 a 2010 Fonte de dados: Divisão Territorial Brasileira, IBGE

Visualizando a evolução do processo de criação de municípios nas diferentes mesorregiões paranaenses, entre os anos de 1950 e 1970, destacam-se a Norte Central e a Noroeste (ambas na porção norte do estado), onde a criação de novos municípios foi particularmente intensa: em vinte anos, são criados 50 novos municípios em cada uma das regiões. Nenhuma outra mesorregião registrou tamanha quantidade de novos municípios no mesmo período.

Com uma evolução menos intensa que as duas mesorregiões anteriores, mas ainda com alto registro de novos municípios destacam-se, por um lado, a Metropolitana de Curitiba, onde são criados 12 novos municípios, entre 1950 e 1970 e, por outro o Norte Pioneiro, que registrou a criação de vintes municípios no mesmo período.

Duas outras mesorregiões apresentaram trajetórias peculiares: a Sudoeste sai de zero município, em 1950, para 24 municípios, em 1970. Por sua vez, na Oeste aconteceu algo semelhante, passando de 1 para 19 municípios, no mesmo período. Ou seja, é no período 1950-1970 que se constituiu uma rede de municípios nessas duas mesorregiões. 
Ainda com relação ao período 1950-1970, vale destacar aquelas mesorregiões que, contrariamente as mesorregiões anteriores, não assistiram a um processo intenso de criação de novos municípios: é o caso da Centro-Oriental, Centro-Sul e Sudeste onde foram criados, respectivamente, três, quatro e cinco novos municípios, no período.

Para finalizar essa seção, vale destacar a evolução apresentada pelas mesorregiões durante a década de 1990. Nesse período, influenciado pela abertura política e pela Constituição de 1988 que, entre outras coisas, promoveu a autonomia jurídica e financeira dos municípios e deu início ao processo de descentralização político-administrativa, que vai ganhar vulto ao longo dos anos 90, o processo de criação de município foi caracterizado pela permissividade da legislação e pela consequente proliferação de pequenos municípios em todos os estados brasileiros (SERRA e AFONSO, 1999; GOMES e MACDOWELL, 2000).

Com base no que foi exposto, sustenta-se que o processo de criação de município ao longo da década de 1990, dada as características de grande parte dos municípios envolvidos, apresenta um significado distinto daquele que norteou a criação de municípios, cerca de vinte a quarenta anos antes.

Assim, enquanto os municípios criados entre os anos de 1950 e 1970 podem ser considerados como expressão direta do dinamismo econômico e demográfico que caracterizou o período, considera-se que houve o predomínio da dimensão políticainstitucional no processo que originou os municípios ao longo dos anos 90. Ou seja, contrariamente ao período precedente, argumenta-se que se fez uso da criação de municípios, no período recente, como uma ferramenta para promoção de um maior dinamismo econômico, demográfico e social nas áreas onde ocorreu o surgimento de novos municípios.

Dito isso, observa-se que o processo de criação de municípios, na década de 1990, foi particularmente significativo nas mesorregiões Norte Central, Oeste, Centro-Sul, Sudoeste e Metropolitana de Curitiba - um grupo bastante heterogêneo quanto aos diversos aspectos já tratados aqui - destacando-se, ainda, que, embora o Paraná não esteja entre os estados que mais criaram municípios na década de 1990, ele seguiu a tendência nacional por apresentar uma legislação que favoreceu a criação de pequenos municípios. 


\section{Os pequenos municípios e o processo emancipatório recente}

Para complementar o debate desenvolvido aqui, nesta seção serão trabalhados, alguns dados relativos aos municípios criados ao longo da década de 1990 e, em especial, aos pequenos municípios. Porém, antes de tratar dos novos municípios criados, faz-se relevante acompanharmos a evolução do peso dos pequenos municípios no total das municipalidades, ao longo das últimas seis décadas.

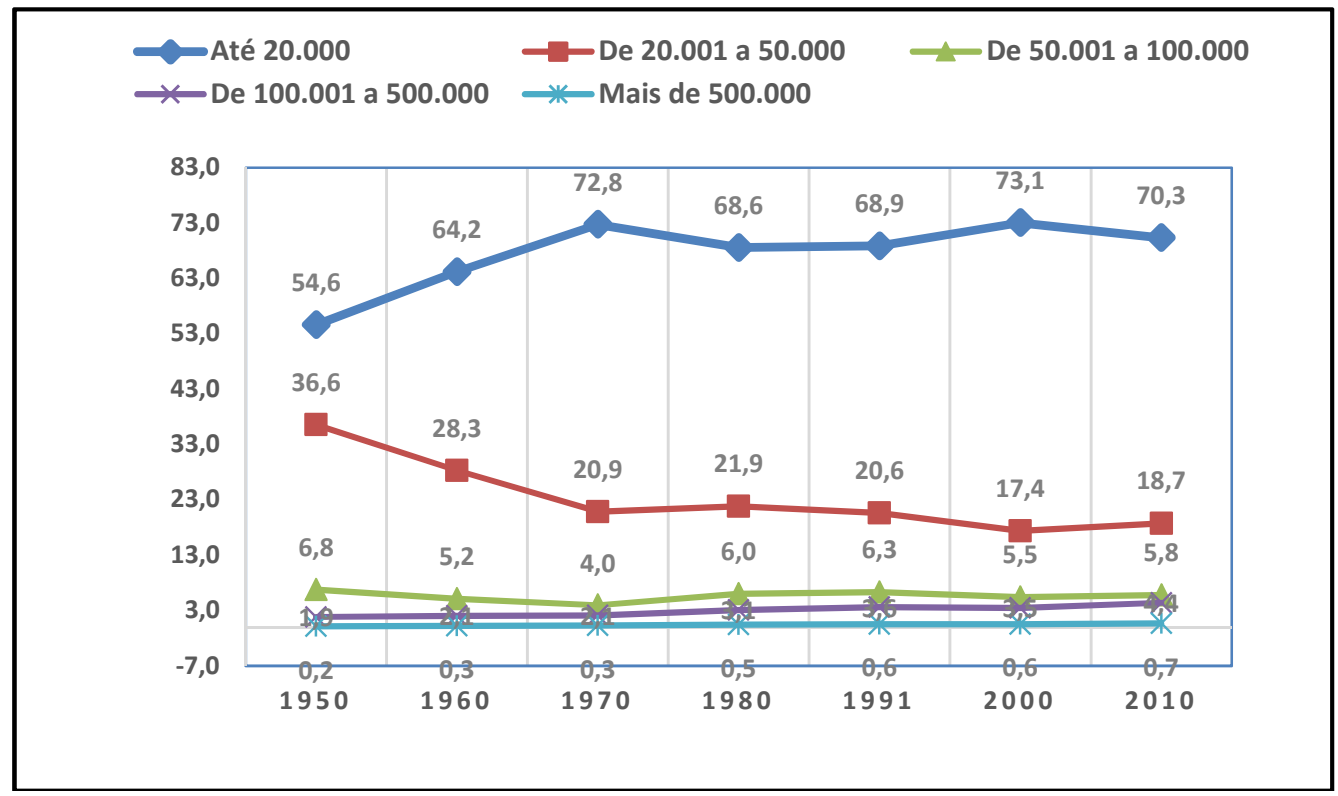

Gráfico 5: Participação (\%) dos municípios, por porte populacional, Brasil 1950 a 2010

Fonte: Censos demográficos, 1950-2010 (IBGE)

Conforme podemos observar no gráfico 6, os pequenos municípios (com população inferior a 20.000 habitantes), entre os anos de 1950 e 2010, apresentaram uma participação relativa crescente, saindo de 54,6\%, em 1950, e alcançando o patamar de 70\%, em 2010. Nesse período, esses valores registraram dois momentos de pico: em 1970 , com $72,8 \%$, e em $2000, \operatorname{com} 73 \%{ }^{4}$.

\footnotetext{
${ }^{4}$ Como o foco desta seção são os municípios de pequeno porte (inferior a 20.000 habitantes), não serão tratadas as informações relativas aos demais grupos de municípios.
} 


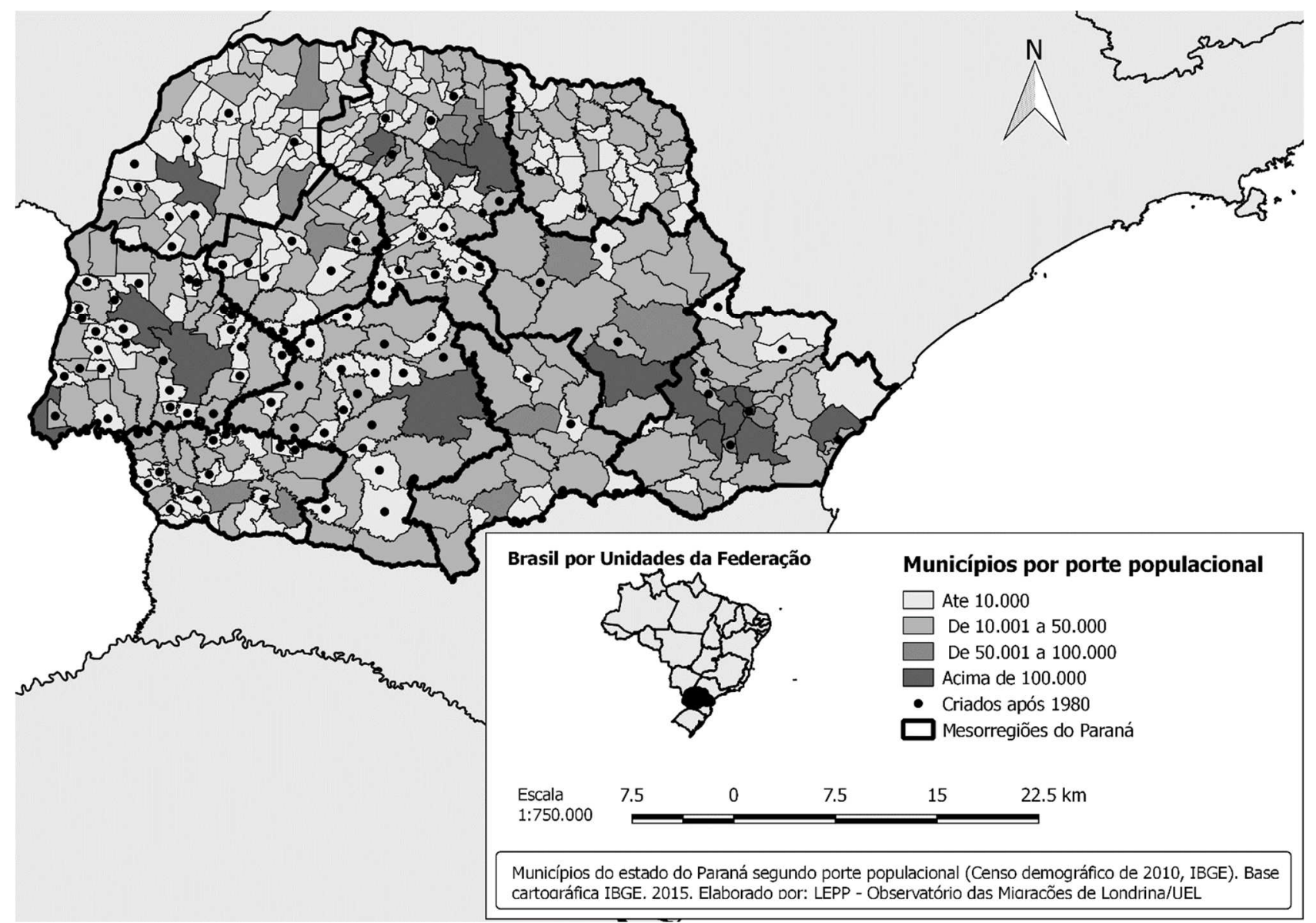

Mapa 2: Municípios do estado do Paraná, Brasil, por porte populacional - 2010

Fonte de dados: Censo Demográfico 2010, IBGE; Base cartográfica, IBGE, 2015. [Elaboração própria]

Conforme pode-se observar no Mapa 2, a maioria dos municípios criados no estado do Paraná a partir de 1980 têm um porte populacional de até 10.000 habitantes. Se, por um lado, os pequenos municípios corresponderam à grande maioria das municipalidades, por outro, esses municípios, embora tenham registrado um crescimento absoluto da população, passando de aproximadamente 11 milhões de pessoas, em 1950, para mais de 32 milhões, em 2010, a proporção concentrada por eles reduziu-se ao longo do tempo, ou seja, em 1950 , esse grupo de município concentrava $23 \%$ da população, em contraste com os $17 \%$, de 2010, sendo o ano de 1970 o momento em que os pequenos municípios alcançaram a mais alta participação relativa do período - cerca de 28\% (gráfico 6). 


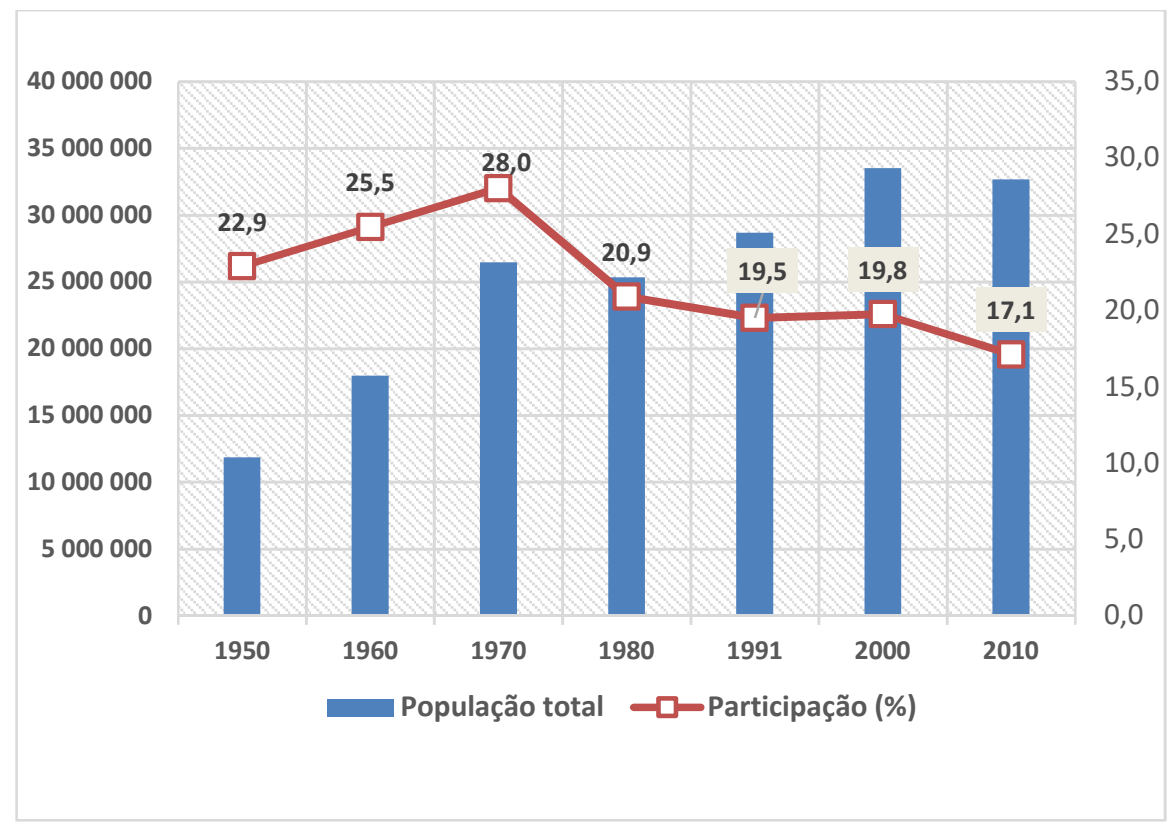

Gráfico 6: População total e participação (\%) dos pequenos municípios (inferior a 20.000 habitantes), Brasil - 1950-2010

Fonte: Censos demográficos, 1950-2010 (IBGE)

Como o centro da polêmica com relação aos pequenos municípios referem-se àqueles de população inferior a 10.000 habitantes e, em especial, os municípios com até 5.000 habitantes, vale destacar a participação relativa desses subgrupos e municípios, ao longo do mesmo período abordado.

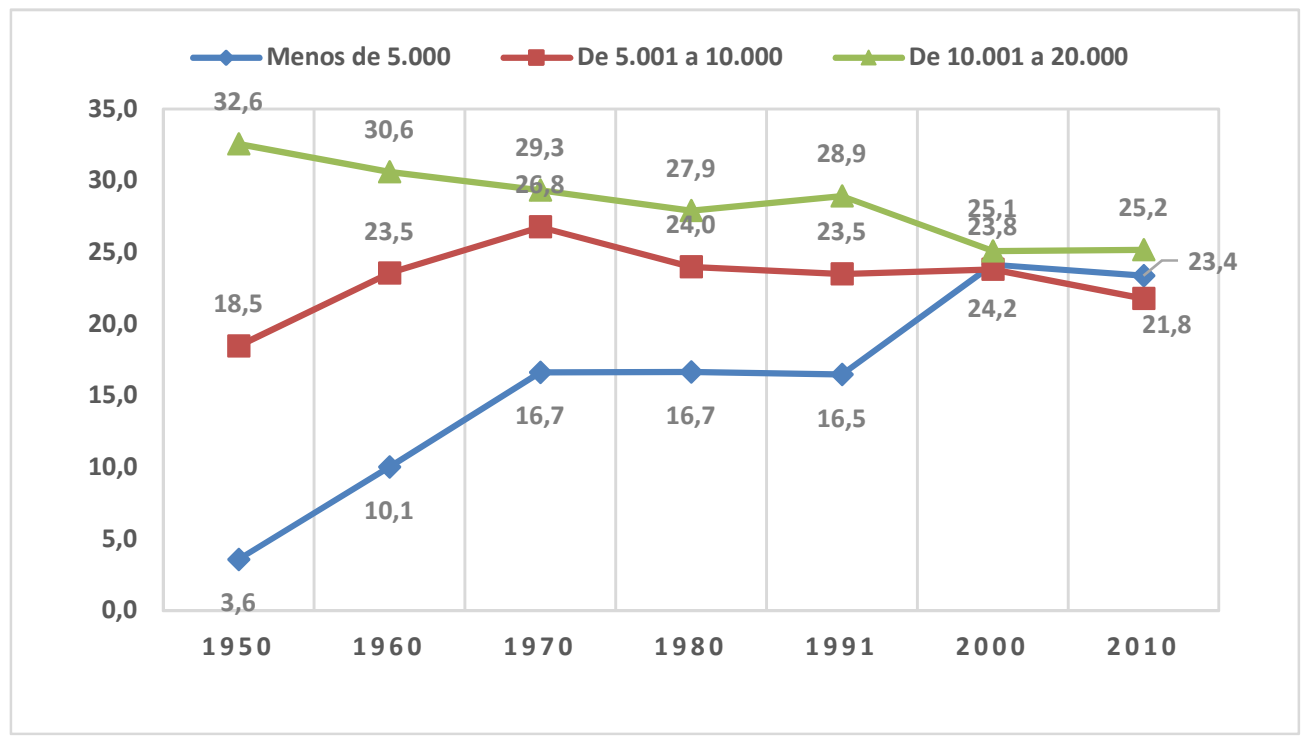

Gráfico 7: Participação (\%) dos municípios de pequeno porte populacional, Brasil 1950 a 2010 Fonte: Censos demográficos, 1950-2010 (IBGE) 
De acordo com o gráfico 8 , os três grupos de pequenos municípios apresentam, individualmente, ao longo do período, evoluções diferenciadas quanto a sua participação relativa no número total de municípios, no país. Nesse sentido, enquanto, em 1950, o grupo de municípios com população entre 10.000 e 20.000 habitantes concentrava 32\% dos municípios brasileiros, os municípios com menos de 5.000 habitantes representavam apenas $3,6 \%$.

Após cinco décadas, fruto tanto da dinâmica demográfica das próprias municipalidades como do processo de criação de municípios, via desmembramento municipal, observamos uma convergência na participação relativa entre os três subgrupos de pequenos municípios: em 2000, esses subgrupos, individualmente, apresentaram participação relativa entre $23 \%$ e $25 \%$ - valores que sofreram poucas mudanças em 2010 e que se mantiveram superiores à participação relativa de qualquer outro grupo de municípios de maior porte populacional (gráfico 5).

Embora esses municípios concentrem, no período mais recente, cerca de 32,6 milhões de pessoas, o que equivale a $17 \%$ da população brasileira (gráfico 6), não há como negar a sua importância no processo de urbanização e na estruturação da rede de cidades do país, uma vez que, devido a sua dimensão numérica, eles se encontram distribuídos por todo o território nacional, e representariam a interiorização do poder público local - o que ganha relevância no contexto no período posterior à Constituição de 1988, caracterizada pelo fortalecimento da autonomia municipal e pela descentralização político-administrativa, que passou para a competência dos executivos municipais parcela significativa da gestão de políticas públicas no âmbito local.

No entanto, a percepção da importância desse papel político-territorial desempenhado pelos pequenos municípios vem perdendo força na medida que nos distanciamos da década de 1990, contexto em que um dos caminhos defendidos para o fortalecimento da democracia e da participação popular estava vinculado à descentralização políticoadministrativa e à autonomia municipal, o mesmo que contribuiu para o processo emancipatório dos anos 1990, caracterizado pela proliferação de pequenos municípios.

Conforme o que já foi apresentado até então, pode-se afirmar que o processo de criação de municípios poucas vezes recebeu visibilidade como uma questão social e política relevante 
para o país. Uma exceção nesse caso refere-se à própria década de 1990, no contexto caracterizado pelo que foi chamado de "proliferação de pequenos municípios" (SERRA e AFONSO, 1999; GOMES e MACDOWELL, 2000).

$\mathrm{Na}$ atualidade, algumas referências a esse momento mais recente do processo de criação de municípios destacam como um aspecto mais negativo o fato de que, no contexto político pós- Constituição de 1988, em todas unidades da federação, a legislação estadual facilitou o surgimento de muitos municípios de pequeno porte municipal, com população inferior a 10.000 habitantes, o que representaria um impacto nocivo nas finanças públicas e na autonomia do governo municipal.

Nessa direção, destaca-se o relatório do Tribunal de Contas do Estado do Paraná (TCE-PR, 2015), que chegou a propor a fusão ou reintegração de pequenos municípios como um caminho para resolver ou amenizar o problema de déficit das finanças públicas no estado posicionamento reforçado pela reportagem do Estado de São Paulo (Dependência crônica, 2017), no qual se enfatiza que boa parte dos pequenos municípios nem deveriam existir, pois, nesse momento de crise, resultado de uma baixo desenvolvimento, há um aumento na dependência crônica desses pequenos municípios em relação ao FPM, comprometendo sua autonomia e atendimento aos munícipes. Discutiremos essa questão à luz dos pequenos municípios paranaenses.

\subsection{Os "velhos" e "novos" pequenos municípios paranaenses}

Durante o processo emancipatório da década de 1990, foram criados em todo Brasil 1.140 novos municípios, dos quais 868 (76\%) são municípios que, em 2010, possuíam população inferior a 10.000 habitantes.

No estado do Paraná, nesse período, foram criados 81 novos municípios, constituindo-se na quinta Unidade da Federação em quantidade de municípios criados, ficando atrás do Rio Grande do Sul, Minas Gerais, Piauí e Santa Catarina ${ }^{5}$. Por sua vez, dentre esses novos municípios paranaenses, 68 são pequenos municípios, com população inferior a 10.000

\footnotetext{
${ }^{5}$ A quantidade de municípios criados nesses estados é a seguinte: RS, com 163 municípios; MG, com 130; PI, com 106; e, por fim, SC, com 87 municípios.
} 
habitantes, de acordo com o censo demográfico de 2010, correspondendo a $84 \%$ dos municípios criados no estado e a $8 \%$ do total de pequenos municípios criado em todo país.

\begin{tabular}{|c|c|c|c|c|c|c|}
\hline \multirow[b]{2}{*}{ MESORREGIÕES } & \multicolumn{3}{|c|}{ TOTAL MUNICÍPIOS } & \multicolumn{3}{|c|}{ NOVOS MUNICÍPIOS } \\
\hline & $\begin{array}{l}\text { Total - Até } \\
10.000 \text { hab }\end{array}$ & $\begin{array}{l}\text { Entre } 10.000 \\
\text { e } 5.001 \mathrm{hab}\end{array}$ & $\begin{array}{l}\text { Menos de } \\
5.000 \mathrm{hab}\end{array}$ & $\begin{array}{l}\text { Total - Até } \\
10.000 \text { hab }\end{array}$ & $\begin{array}{l}\text { Entre } 10.000 \text { e } \\
5.001 \text { hab }\end{array}$ & $\begin{array}{l}\text { Menos de } \\
5.000 \text { hab }\end{array}$ \\
\hline Norte Central & 46 & 18 & 28 & 11 & 1 & 10 \\
\hline Norte Pioneiro & 27 & 14 & 13 & 1 & 0 & 1 \\
\hline Noroeste & 43 & 23 & 20 & 8 & 2 & 6 \\
\hline Centro-Ocidental & 12 & 5 & 7 & 3 & 0 & 3 \\
\hline Porção Norte & 128 & 60 & 68 & 23 & 3 & 20 \\
\hline Metrop. Curitiba & 7 & 6 & 1 & 2 & 2 & 0 \\
\hline Centro-Oriental & 1 & 1 & 0 & 1 & 1 & 0 \\
\hline Oeste Paranaense & 27 & 15 & 12 & 17 & 7 & 10 \\
\hline Centro-Sul & 13 & 7 & 6 & 13 & 7 & 6 \\
\hline Sudeste & 6 & 5 & 1 & 2 & 2 & 0 \\
\hline Sudoeste & 21 & 11 & 10 & 10 & 2 & 8 \\
\hline Porção Sul & 75 & 45 & 30 & 45 & 21 & 24 \\
\hline PARANÁ & 203 & 105 & 98 & 68 & 24 & 44 \\
\hline
\end{tabular}

Tabela 6: Total de pequenos municípios existentes e pequenos municípios criados na década de 1990, mesorregiões do Paraná, 2010

Fonte: Divisão territorial Brasil e Censo demográfico de 2010 (IBGE)

Com os dados da tabela 6 , observa-se que esses 68 novos municípios correspondem a aproximadamente $34 \%$ do total dos 203 municípios existentes em $2010^{6}$. Ou seja, 2/3 dos atuais pequenos municípios paranaenses foram criados antes da década marcada pela "proliferação" de pequenos municípios no país.

Por sua vez, quando nos voltamos para as duas porções territoriais consideradas, observamos duas situações diferentes: na porção sul, de ocupação mais antiga do estado, que inclui a capital do estado, há uma menor presença relativa de pequenos municípios

\footnotetext{
${ }^{6}$ Atualmente, o Paraná possui 399 municípios, sendo que aqueles com população inferior a 10.000 habitantes correspondem a 51\% dos municípios paranaenses. Segundo dados do censo demográfico de 2010, essa proporção é inferior às correspondentes aos estados do Piauí (73\%), Rio Grande do Sul (67\%), Santa Catarina (59\%) e Minas Gerais (58\%).
} 
(75), porém 60\% deles foram criados nos anos 90; por outro lado, na porção norte, de ocupação mais recente vinculada à expansão da fronteira agrícola paranaense, há um maior número de pequenos municípios (128), porém com uma baixa participação de novos municípios (18\%).

Isso nos dá um elemento adicional para contrastar com o diagnóstico e prescrição do TCEPR (2015), que sugere a fusão de pequenos municípios como uma solução para o déficit nas finanças públicas municipais, utilizando na sua justificativa a criação indevida de muitos pequenos municípios no contexto pós-Constituição de 1988, caracterizado pela "facilitação" da criação de pequenos e micro municípios que, segundo alguns observadores (Gomes e Macdowell, 2000; Serra e Afonso, 1999), não teriam condições de autonomia e auto sustentação.

A distribuição dos "velhos" e "novos" pequenos municípios nas diferentes mesorregiões paranaenses nos permite destacar que o processo de criação de municípios mais recente teve significados diferentes nas diferentes porções territoriais do estado, que possuem históricos de desenvolvimento econômicos e demográficos específicos, e essas especificidades precisam ser consideradas no entendimento da complexidade desse fenômeno emancipatório que, no nosso entendimento, não foi uma mera expressão de uma legislação permissiva que teria permitido uma "ação predatória" por parte de uma multiplicidade de localidades interessadas somente em deter para si uma parcela do Fundo de Participação dos Municípios (FPM), como faz parecer os contrários ao processo emancipatório a década de $1990^{7}$.

O TCE-PR (2015) sustenta esse posicionamento justificando-o através da exposição de dois tipos de informações: as relativas às finanças municipais (componentes da receita municipal e tipos de despesas municipais) e o Índice de Desenvolvimento Humano Municipal (IDHM) de 2010. Destaca-se ainda que o recorte espacial da análise compreendeu os decis inferior e superior, ou seja, comparando-se os municípios entre os $10 \%$ menos populosos e os $10 \%$ mais populosos.

No balanço desta análise, chegou-se à consideração de que os municípios menos populosos vivenciavam uma situação que tendia a se reforçar no tempo: baixa capacidade de

\footnotetext{
${ }^{7}$ Em SIQUEIRA (2003), a autora apresenta a polarização presente na época entre os grupos e instituições "defensores" e os "contrários" ao processo de criação de municípios ocorrido durante a década de 1990.
} 
arrendação própria, com destaque para a grande dependência em relação ao FPM, resultando em baixo investimento dos municípios em áreas sociais importantes e, por isso, essa situação se evidenciaria no baixo valor do IDH-M correspondente.

Porém, na nossa avaliação, a leitura da situação dos pequenos municípios paranaenses, feita pelo relatório do TCE-PR, apresenta limitações, dentre as quais selecionamos algumas para serem discutidas de forma mais detida. Primeiramente, abordaremos duas: o uso do IDH-M sem uma perspectiva crítica sobre a construção do indicador e a ausência de um recorte territorial que considere as diferentes regiões do estado.

De acordo com os estudos de Guimarães e Jannuzzi (2005) e Barreto e Jannuzzi (2012), o Índice de desenvolvimento humano municipal (IDH-M) constitui-se num indicador sintético ${ }^{8}$, ou medida-resumo, construído a partir do Índice de Desenvolvimento Humano (IDH) que, por sua vez, foi elaborado pelos economistas asiáticos Mahbub ul Haq e Amartya Sen para contrastar com o indicador amplamente usado desde a década de 1950, para medir o nível de desenvolvimento dos países - o PIB per capita.

Em termos gerais, o IDH busca medir o nível de desenvolvimento de um pais numa perspectiva mais ampla do que a proporcionada pelo PIB per capita, considerando as dimensões sociais de educação, longevidade e renda e, desde 1990, o Programa das Nações Unidas para o Desenvolvimento (PNUD) publica anualmente o índice para os países (Guimarães e Jannuzzi, 2005).

Por sua vez, o IDH-M foi elaborado numa parceria entre o PNUD, o Instituto de Pesquisas Econômicas Aplicadas (IPEA) e a Fundação João Pinheiro, com o objetivo de atender a especificidade dos municípios brasileiros. Afirma-se, a partir da literatura especializada que, assim como o IDH, o IDH-M possui o mérito de trazer para a reflexão sobre o desenvolvimento as dimensões sociais relacionadas com a longevidade, a educação e a renda, a partir de informações de fácil entendimento e produzidas com regularidade, tendo como base os censos demográficos realizados decenalmente pelo IBGE 9 .

\footnotetext{
${ }^{8}$ Segundo Scandar Neto et al. (2008), indicadores sintéticos são aqueles "que se propõem a apreender a realidade social através de uma única medida, resultante da combinação de múltiplas medições das suas dimensões analíticas quantificáveis". (SCANDAR NETO et.al, 2008, p.2)

${ }^{9}$ Os componentes que constituem o IDH-M são os seguintes: Dimensão longevidade: esperança de vida ao nascer; Dimensão educação: a escolaridade da população adultas (\% pessoas de 18 anos ou mais com ensino
} 
Em contrapartida, no IDH-M persistem importantes desvantagens também identificadas no $\mathrm{IDH}^{10}$. Nesse sentido, podemos destacar a pouca sensibilidade do indicador em captar as efeitos na realidade da implementação de determinadas políticas e ações do poder público, devido à própria limitação das medidas consideradas no cômputo do índice e à sua limitação temporal, uma vez que a base de dados utilizada para o cálculo é o censo demográfico decenal, contribuindo para um descompasso temporal entre o indicador e a realidade, na medida em que nos distanciamos do ano de realização do censo demográfico.

Isso nos leva a uma segunda desvantagem do indicador que se refere ao emprego do IDH-M como única medida para avaliação ou definição de políticas públicas. Devido às limitações apresentadas anteriormente, não é recomendável a tomada de decisão política baseada unicamente num indicador sintético, como o IDH-M, pois ele não dá conta de toda a complexidade e da questão social considerada.

Contudo, apesar dessas considerações, optou-se por manter aqui a consideração dos municípios paranaenses a partir da informação do IDH-M para estabelecer um diálogo com o argumento do TCE-PR, porém com o diferencial de apresentar esses dados com um recorte espacial diferente.

Nesse sentido, na tabela 7, o IDH-M dos municípios paranaenses são apresentados, nas suas diferentes dimensões, para as diferentes mesorregiões do estado, nos anos de 2000 e 2010. Optou-se por calcular a média simples dos valores do IDH-M dos municípios por mesorregião, por considerar que, dessa forma, poderia se captar a tendência desses indicadores em cada região, mesmo conhecimento as limitações desse tipo de cálculo, por se ocultar os valores extremos.

Podemos observar que, entre 2000 e 2010, nas três dimensões, os valores médios do IDH-M cresceram, ou melhoraram ${ }^{11}$, em todas as mesorregiões, sendo os maiores valores registrados na dimensão longevidade, seguidos pelos valores na dimensão renda e, por fim, os da dimensão educação. Considerando-se, por sua vez, a evolução dos valores no tempo,

fundamental completo) e o fluxo escolar da população jovem (\% crianças e jovens que frequentam escola na série correspondente); Dimensão renda: renda municipal per capita.

${ }^{10}$ Para um debate completo sobre as vantagens e desvantagens do IDH e IDH-M, ver Guimarães e Jannuzzi (2005) e Barretos e Jannuzzi (2012).

${ }^{11}$ Os valores do IDH-M variam entre 0 e 1 , apresentando as seguintes faixas de desenvolvimento humano: 1 ) 0,000 a 0,499 (muito baixo); 2) 0,500 a 0,599 (baixo); 3) 0,600 a 0,699 (médio); 4) 0,700 a 0,799 (alto); 5) 0,800 e mais (muito alto). 
nota-se que os maiores ganhos foram registrados na dimensão educação, o que foi observado em todas as mesorregiões.

\begin{tabular}{l|cc|cc|cc}
\hline \multirow{2}{*}{ MESORREGIÕES } & \multicolumn{2}{|c|}{ IDHM Longevidade } & \multicolumn{2}{c|}{ IDHM Educação } & \multicolumn{2}{c}{ IDHM Renda } \\
\cline { 2 - 7 } & $\mathbf{2 0 0 0}$ & $\mathbf{2 0 1 0}$ & $\mathbf{2 0 0 0}$ & $\mathbf{2 0 1 0}$ & $\mathbf{2 0 0 0}$ & $\mathbf{2 0 1 0}$ \\
\hline Norte Central & 0,758 & 0,825 & 0,477 & 0,632 & 0,614 & 0,687 \\
Norte Pioneiro & 0,739 & 0,813 & 0,450 & 0,620 & 0,610 & 0,674 \\
Noroeste & 0,748 & 0,815 & 0,467 & 0,617 & 0,603 & 0,685 \\
Centro Ocidental & 0,734 & 0,811 & 0,416 & 0,609 & 0,590 & 0,673 \\
\hline Porção Norte & $\mathbf{0 , 7 4 5}$ & $\mathbf{0 , 8 1 6}$ & $\mathbf{0 , 4 5 3}$ & $\mathbf{0 , 6 2 0}$ & $\mathbf{0 , 6 0 4}$ & $\mathbf{0 , 6 8 0}$ \\
\hline Metrop. Curitiba & 0,743 & 0,807 & 0,375 & 0,544 & 0,590 & 0,669 \\
Centro Oriental & 0,712 & 0,798 & 0,369 & 0,543 & 0,602 & 0,633 \\
Oeste & 0,755 & 0,818 & 0,474 & 0,618 & 0,615 & 0,699 \\
Centro-Sul & 0,726 & 0,811 & 0,303 & 0,527 & 0,571 & 0,627 \\
Sudeste & 0,721 & 0,805 & 0,386 & 0,590 & 0,587 & 0,669 \\
Sudoeste & 0,755 & 0,820 & 0,428 & 0,611 & 0,601 & 0,691 \\
\hline Porção Sul & $\mathbf{0 , 7 3 5}$ & $\mathbf{0 , 8 1 0}$ & $\mathbf{0 , 3 8 9}$ & $\mathbf{0 , 5 7 2}$ & $\mathbf{0 , 5 9 4}$ & $\mathbf{0 , 6 6 5}$ \\
\hline
\end{tabular}

Tabela 7: IDH-M Longevidade, Educação e Renda, Mesorregiões do Paraná, 2000 e 2010 Fonte de dados: IPEA, PNUD, Fundação João Pinheiro, 2000 e 2010 [disponibilizados pelo IPARDES]

No entanto, a principal contribuição desse recorte espacial é poder visualizar, a partir desse indicador selecionado, o diferencial existente entre as mesorregiões do estado. Assim, mesmo com as limitações do IDH-M para dimensionar a complexidade do desenvolvimento social, o nosso objetivo é demonstrar a importância de se considerar um recorte regional para esse tipo de análise.

Assim, de acordo com a tabela 7, onde há uma organizações das mesorregiões entre duas porções territorial do estado, observa-se que a porção norte, que incluir a região de Londrina - segundo município mais populoso do estado e a sede da expansão da fronteira agrícola e da cafeicultura a partir das década de 1930 - apresenta valores de IDH-M superiores à porção da região sul, de ocupação mais antiga e onde se localiza a capital estadual. 
Por sua vez, com os dados da tabela 8 , buscou-se visualizar o valor médio do IDH-M total, de 2010, considerado por mesorregiões e portes populacionais.

\begin{tabular}{|c|c|c|c|c|c|c|}
\hline MESORREGIÕES & $\begin{array}{c}\text { Acima de } \\
100.000 \text { hab }\end{array}$ & $\begin{array}{c}100.000 \mathrm{a} \\
50.001 \mathrm{hab}\end{array}$ & $\begin{array}{c}50.000 \mathrm{a} \\
20.001 \mathrm{hab}\end{array}$ & $\begin{array}{c}20.000 \mathrm{a} \\
10.001 \text { hab }\end{array}$ & $\begin{array}{c}10.000 \mathrm{a} \\
5.001 \text { hab }\end{array}$ & $\begin{array}{c}\text { Até } 5.000 \\
\text { hab }\end{array}$ \\
\hline Norte Central & 0,771 & 0,723 & 0,734 & 0,697 & 0,708 & 0,712 \\
\hline Norte Pioneiro & * & 0 & 0,729 & 0,696 & 0,692 & 0,703 \\
\hline Noroeste & 0,761 & 0,759 & 0,721 & 0,705 & 0,699 & 0,702 \\
\hline Centro Ocidental & $*$ & 0,757 & 0,735 & 0,703 & 0,689 & 0,696 \\
\hline Porção Norte & 0,766 & 0,746 & 0,730 & 0,700 & 0,697 & 0,703 \\
\hline Metrop. Curitiba & 0,750 & 0,710 & 0,705 & 0,672 & 0,626 & 0,700 \\
\hline Centro Oriental & 0,763 & 0,719 & 0,687 & 0,669 & 0,650 & $*$ \\
\hline Oeste & 0,767 & $*$ & 0,743 & 0,713 & 0,705 & 0,707 \\
\hline Centro-Sul & 0,731 & $*$ & 0,686 & 0,633 & 0,635 & 0,654 \\
\hline Sudeste & * & 0,733 & 0,685 & 0,665 & 0,679 & 0,685 \\
\hline Sudoeste & $*$ & 0,778 & 0,717 & 0,710 & 0,708 & 0,694 \\
\hline Porção Sul & 0,753 & 0,735 & 0,704 & 0,677 & 0,667 & 0,688 \\
\hline
\end{tabular}

Tabela 8: IDHM Total, segundo classes populacionais de municípios Mesorregiões do Paraná, 2010

Fonte de dados: IPEA, PNUD, Fundação João Pinheiro, 2010 [disponibilizados pelo IPARDES]

* Não há município no porte correspondente, na mesorregião

Mais uma vez, observa-se um diferencial em favor da porção norte quando comparada com a sul, para todos os recortes populacionais de municípios, além de haver, nos grupos com população inferior a 50.000 habitantes, diferenciais entre regiões localizadas numa mesma porção territorial.

Porém, o que se pretende destacar com esse recorte espacial é que não há uma relação direta entre porte populacional e valores de IDH-M, no sentido dos menores municípios apresentarem, necessariamente, os menores índices. Pelo contrário, o que se verifica nas porções norte e sul, nas três classes populacionais inferiores, é que o grupo dos municípios com população inferior a 5.000 habitantes apresenta um valor médio de IDH-M maior que os valores referentes aos dois grupos imediatamente superiores.

Com isso, o argumento contrário à criação de pequenos municípios e a defesa à fusão de municípios, baseado numa baixa avaliação do desenvolvimento social dos municípios, 
conforme exposto no relatório do TCE-PR (2015), perdem sua sustentação uma vez que, em primeiro lugar, diferentes recortes espaciais podem revelar diferentes cenários dos indicadores utilizados e, em segundo lugar, uma tomada de decisão do poder público não pode ser basear na consideração de um único indicador social.

Com isso, chegamos às duas últimas limitações presentes no relatório do TCE-PR, que se referem à utilização de um único indicador como proxy para a avaliação da qualidade de vida nos municípios e o pressuposto de que somente o governo municipal é responsável pelos valores registrados pelo IDH-M.

Assim, nem o IDH-M tem informação suficiente para sustentar, exclusivamente, quaisquer decisões políticas - muito menos as que envolvam questões tão complexas como fusão de municípios - e nem se deve considerar a qualidade de vida nos municípios como resultado da ação exclusiva do governo municipal.

Ao invés disso, deveria se considerar essa qualidade de vida como resultado da convergência entre diferentes ações, nem sempre articuladas no tempo e espaço, das esferas locais, estaduais e federal de governo, e não somente indicadores sociais, voltados para áreas de saúde e educação, mas de forma especial as ações direcionadas para o desenvolvimento econômico estadual, em grande parte, responsáveis pela desigualdade regional em termos de geração de renda e recursos públicos.

\section{Considerações Finais}

O processo de criação de municípios no Brasil não recebeu atenção proporcional à importância do fenômeno no país, sendo que a maioria dos estudos realizados referem-se ao período da década de 1990, com estudos acadêmicos realizados nas áreas de Economia, Ciência Política e Geografia, e com o debate sendo polarizado por instituições de assessoria 
aos governos municipais, como o Instituto Brasileiro de Administração Municipal (IBAM), por um lado, e de institutos vinculados ao governo federal, como o Instinto de Pesquisa Economia Aplicada (IPEA), por outro ${ }^{12}$.

Este é um debate que tem sido tratado em diferentes países, sobretudo em relação aos processos de centralização e descentralização de governos locais no âmbito de políticas fiscais, planejamento urbano, processos migratórios, conflitos de identidades regionais e sobretudo como forma de equilíbrio entre unidades federativas subnacionais.

O processo ocorrido no Brasil pode ser base para estudos comparativos futuros com os casos do México, estudado por Grindel (2009), a reforma de 2007 na Dinamarca, analisada por Blom-Hansen (2010) e para o caso do debate federativo na Europa Ocidental, o trabalho de Swenden (2006).

Essa carência de estudos sobre a temática no Brasil, principalmente estudos que cubram um período maior de tempo e os articule a partir de diferentes dimensões, como a demográfica, a econômica e a política, tem apresentado seus efeitos deletérios no momento atual, quando o tema volta a surgir na mídia, em função dos vetos por parte do governo federal na fase mais recente de uma tramitação de propostas de alterações no processo de criação de municípios, que teve início há mais de vinte anos.

O desafio que a contemporaneidade coloca é que a volta ao cenário público dessa questão está sendo feita desacompanhada das bandeiras presentes na década de 1990, voltadas à defesa da autonomia política e da participação popular, que animaram o polo favorável às emancipações municipais de pequenos municípios por todo o país.

Ao contrário, vem ganhando força uma narrativa que enxerga o processo de criação de municípios dos anos 1990 e os pequenos municípios, em particular, como a causa dos problemas financeiros e de gestão vivenciados pelo governo municipal, em geral, onde a proposta de fusão de municípios é colocada como decisão tecnocrata em resposta a uma avaliação objetiva de indicadores de finanças públicas e de qualidade de vida.

A fusão de municípios vem sendo prevista nas constituições federais ao longo do período republicano, no Brasil, embora, em pouquíssimos momentos, esse mecanismo tenha sido acionado. Já no cenário internacional, conforme aponta a literatura sobre processos em

\footnotetext{
12 Um balanço sobre o debate pode ser encontrado em Siqueira (2003).
} 
curso em países desenvolvidos, essa opção tem sido buscada, principalmente, como forma de equacionar questões orçamentárias e de prestação de serviços públicos, como ilustrado por matéria divulgada em 2016 (PIAGINIANI, 2016), sobre duas pequenas cidades na Toscana, Itália - Montalcino e San Giovanni d'Asso - que decidiram se fundir para resolver problemas relativos à continuidade na oferta dos serviços públicos municipais.

O que chama a atenção no caso italiano é que tal decisão partiu de uma deliberação conjunta, que envolveu o governo local e a população das duas cidades, ou seja, tratou-se de uma decisão autônoma e participativa das localidades interessadas. Além disso, um dos pontos recorrentes no debate internacional é que a fusão municipal - "municipal amalgamation", "municipal merger" - não leva, necessariamente, à redução orçamentária ou à melhoria na prestação de serviços públicos. Muitos outros aspectos devem ser considerados.

Com isso, finaliza-se essas considerações destacando que uma proposição tão complexa, como a de fusão de pequenos municípios, não deveria ser tomada numa avaliação baseada em elementos, que podem ser considerados arbitrários, frágeis e pouco robustos, e, principalmente, sem levar em conta aspectos importantes do debate durante a década de 1990, que se referem à a autonomia política municipal e à participação da sociedade civil nas esferas locais.

\section{Referências bibliográficas}

BARRETO, Rafael S.; JANNUZZI, Paulo M. Uma análise acerca das limitações do IDH com respeito às ações e programas do MDS. Estudo Técnico SAGI 13/2012. Brasília: SAGI/MDS, 2012. Disponível em: http://aplicacoes.mds.gov.br/sagirmps/simulacao/estudos tecnicos/pdf/ETEC-13-2012-IDH-DS\%20uma\%20an\%C3\%A1lise\%20acerca\%20das\%20limita\%C3\%A7\%C3\%B5es\%20do\%20IDH\%20com\%20respeit o\%20\%C3\%A0s\%20a\%C3\%A7\%C3\%B5es\%20e\%20programas\%20do\%20MDS. Acesso em: 23/07/2017.

BREMAEKER, François E.J. A importância do FPM para as finanças municipais e seu papel na equalização das receitas. Salvador: Transparência Municipal, julho de 2010. (Estudo Técnico no.105). Disponível em: < http://www.oim.tmunicipal.org.br/abre documento.cfm?arquivo= repositorio/ oim/ documentos/1EC483B1 -EED6-6528-35B1E4E67F39179129072010121409.pdf\&i=1147>. Acessado em: 09/02/2017.

BLESSE, Sebastian; BASKARAN, Thushyanthan. Do municipal mergers reduce costs? Evidence from a German federal state. Discussion Paper n.176, Center for European, Governance and Economic Development Research (CEGE), Gottingen/DE, December 2013. 
BLOM-HANSEN, J. Municipal Amalgamations and Common Pool Problems: The Danish Local Government Reform in 2007. Scandinavian Political Studies, 33: 51-73, 2010.

CANO, Wilson. Urbanização: sua crise e revisão do seu planejamento. Revista de Economia Política. São Paulo, vol.9, no.5, janeiro/março de 1989.

CARVALHO, José Alberto M. O crescimento populacional e a estrutura demográfica no Brasil. Belo Horizonte: UFMG/CEDEPLAR, 2004. (Texto para Discussão, 227)

CIGOLINI, Adilar O. Território e Fragmentação: análise do processo recente de criação de municípios no Paraná. Ra'e Ga - O espaço geográfico em análise, Curitiba, v. 05, n. ano I, p. 47-67, 2001.

CUNHA, José Marcos Pinto. Redistribuição espacial da população: tendências e trajetórias. São Paulo em Perspectiva, São Paulo, 17(3-4), 2003.

DEPENDÊNCIA crônica. Estado de São Paulo, São Paulo, 13 fev.2017. Opinião. Disponível em: < http://opiniao.estadao.com.br/noticias/geral,dependencia-cronica,70001663081>. Acesso: 21/07/2017.

EGGER, Peter H.; KOTHENBURGER, Marko; LOUMEAU, Gabriel. Municipal merger and local activity : evidence form Germany. 73rd. Annual Congresso f the International Institute of Public Finance (IIPF), Tokyo, Japan, August 2017.

FARIA, Vilmar. O sistema urbano brasileiro: um resumo das características e tendências recentes. Estudos CEBRAP 18. São Paulo, out-dez 1976.

GOMES, G. M. e MAC DOWELL, M. C. Descentralização política, federalismo fiscal e criação de municípios: o que é mau para o econômico nem sempre é bom para o social. Texto para Discussão n.o 706, Brasília: IPEA, 2000.

GRINDLE. Merilee S. Going Local: Decentralization, Democratization, and the Promise of Good Governance. Princeton: Princeton University Press, 2009.

GUIMARÃES, José Ribeiro S.; JANNUZZI, Paulo M. IDH, indicadores sintéticos e suas aplicações em políticas públicas. Uma análise crítica. Revista Brasileira de Estudos Urbanos e Regionais, vol.7, n.1, maio/2005. Disponível em: < http://rbeur.anpur.org.br/rbeur/article/view/136>. Acessado em: 25/07/2017.

INSTITUTO PARANAENSE DE DESENVOLVIMENTO ECONÔMICO E SOCIAL. Leituras regionais. Mesorregiões geográficas paranaenses: Sumário executivo. Curitiba: IPARDES, 2004.

INSTITUTO PARANAENSE DE DESENVOLVIMENTO ECONÔMICO E SOCIAL. As migrações e a transformação da estrutura produtiva e fundiária no Paraná. Curitiba: IPARDES, 1983.

KAUDER, Bjorn. Incorporation of municipalities and population growth. A propensity score matching approach. Ifo working paper no188, september 2014.

KUSHNER, Joseph; SIEGEL, David. Citizens' atitudes toward municipal amalgamation in three Ontario municipalities. Canada Journal of Regional Science, XXVI:1, Spring 2003, 49-59.

MAGALHÃES, M.B. Paraná: política e governo. Curitiba: SEED, 2001. (Coleção história do Paraná; Textos introdutórios).

MARCILIO, M.L. Crescimento histórico da população brasileira até 1872. Cadernos CEBRAP 16. São Paulo, 1974.

MARTINE, George; CAMARGO, Lício. Crescimento e distribuição da população brasileira: tendências recentes. Revista Brasileira de Estudos de População, Campinas, vol.1, no. 1-2, pp.99-143, jan/dez, 1984.

MARTINE, George; MCGRAHAN, G. Transição urbana brasileira: trajetória, dificuldades e lições aprendidas. In: BAENINGER, Rosana. (org.). População e cidades: subsídios para o planejamento e para as políticas sociais. Campinas: Núcleo de Estudos de População - Nepo/Unicamp; Brasília: UNFPA, 2010.

ROLIM, C.F.C. O Paraná urbano e o Paraná do agrobusiness: as dificuldades para a formulação de um projeto político. Revista Paranaense de Desenvolvimento. IPARDES: Curitiba, no.86, set-dez 1995.

PACHECO, Carlos A. e PATARRA, Neide. Movimentos migratórios anos 80: novos padrões? Encontro Nacional sobre Migração, 1998. Anais... Curitiba: ABEP/IPARDES, 1997. 
PIANIGIANI, Gaia. Cidades na Toscana estudam fusão. Estado de São Paulo, São Paulo, 27 ago.2016. Economia. Disponível em: http://economia.estadao.com.br/noticias/geral,cidades-da-toscana-estudamfusao,10000072330. Acesso: 11/02/2017

SCANDAR NETO, Wadih J.; JANNUZZI, Paulo M.; SILVA, Pedro L.N. Sistemas de indicadores ou indicadores sintéticos: do que precisam os gestores de programas sociais. In: XVI Encontro Nacional de Estudos Populacionais. Anais..., Caxambu, 2008.

SERRA, José. e AFONSO, J.R.R. Federalismo fiscal à brasileira: algumas reflexões. Revista do BNDES, Rio de Janeiro, v.6, no.12, dez.1999.

SHIMIZU, Naoki. Effects of municipal mergers in Japan. Canadian Political Science Association, Annual Conference, Victoria, Canada, Jun 2013.

SIQUEIRA, Cláudia Gomes de. Emancipação municipal pós-Constituição de 1988: um estudo do processo de criação dos novos municípios paulistas. Campinas, 2003. Dissertação (Mestrado em Ciência Política) - Instituto de Filosofia e Ciências Humanas, Universidade Estadual de Campinas.

SUZUKI, Kohei; HA, Hyesong. Municipality merger and local democracy: an assessment of the merger of Japanese municipalities. QoG Working Paper Serie, july 2017.

SWENDEN, Wilfried. Comparative Federalism and Regionalism in Western Europe: a Conceptual Overview. In: Federalism and Regionalism in Western Europe. Londres: Palgrave Macmillan 2006.

TOMIO, Fabricio R. L. A criação de municípios após a Constituição de 1988. Revista Brasileira de Ciências Sociais, v. 17, n. 48, p. 61-89, fev. 2002.

TRIBUNAL DE CONTAS DO ESTADO DO PARANÁ (TCE-PR), Estudo de viabilidade municipal. Tribunal de Contas do Estado do Paraná, Curitiba, novembro de 2015. Disponível em: < http://www1.tce.pr.gov.br/conteudo/estudo-de-viabilidade-municipal/296299/area/10>. Acessado em: 15/01/2017. 